
May 1937

\title{
CONFIGURATION OF THE PYRANOSES IN RELATION TO THEIR PROPERTIES AND NOMENCLATURE ${ }^{1}$
}

\author{
By Horace S. Isbell
}

\begin{abstract}
Optical rotation, mutarotation, and bromine oxidation measurements are reported for seven heptoses. The results reveal striking similarity in the properties of the sugars classified in the following groups: (1) $\alpha$ - $l$-arabinose, $\alpha$ - $d$-galactose, $\alpha$ - $d$ - $\alpha$-mannoheptose, and $\alpha$-l- $\beta$-guloheptose; (2) $\beta$-l-arabinose $\mathrm{CaCl}_{2} .4 \mathrm{H}_{2} \mathrm{O}, \beta-d$ galactose, $\beta$ - $d$ - $\alpha$-mannoheptose; (3) $\beta$ - $d$-glucose, and $\beta$-l- $\beta$-galaheptose; (4) $\alpha$ - $d$ lyxose, $\alpha$ - $d$-mannose, and $\alpha$-l- $\alpha$-galaheptose; (5) $\beta$ - $d$-gulose and $\beta$ - $d-\alpha$-glucoheptose. The marked parallelism is evidence that the sugars in each group have like conformations for the pyranose ring.

The structural characteristics of the alpha and beta sugars are discussed in relation to their reactions and their nomenclature. The rates of reaction and other properties indicate that there is an important structural difference in the alpha and beta sugars. This difference is in accord with the concept that the pyranose ring is of the strainless multiplanar type rather than monoplanar. The application of Hudson's rule for selecting the alpha and beta names is considered, and it is suggested that an additional criterion be added to this rule in order to obtain a nomenclature for the carbohydrates and their derivatives, based on the most fundamental structural properties in relation to the optical rotations, together with the theory of optical superposition. Comparisons of the optical rotations of the hexose sugars give values for the rotational differences which may be grouped according to the configurations of the neighboring atoms. The rotational differences obtained from substances of similar or related configuration agree; the rotational differences obtained by the comparison of substances of widely different configuration are not in agreement.
\end{abstract}

\section{CONTENTS}

Page

I. Correlations of optical rotation and structure

II. Nomenclature of the alpha and beta sugars _...

III. Mutarotations of the heptoses and the structurally related hexoses_.. - 515

IV. Conformation of the pyranose ring _._.

V. Bromine oxidation measurements

VI. Summary _. _ _ _ _ _ _ _ _ _ _ _ _

VII. References

\section{CORRELATIONS OF OPTICAL ROTATION AND STRUCTURE}

The elucidation of the configurational interrelationships of the simple sugars by $\mathrm{E}$. Fischer and others, and the unraveling of the problem of ring structure leave as an outstanding problem the determination of the conformation of the sugar molecule as a whole. Study of the relationship between structure and optical rotation was

${ }^{1}$ A résumé of this paper was given before the Division of Sugar Chemistry of the American Chemical Society in September 1936 at Pittsburgh. 
begun by Van't Hoff [1] ${ }^{2}$, who advanced the principle of optical superposition. According to this principle, the optical rotation of the molecule is equal to the algebraic sum of the rotations due to the constituent carbon atoms, the rotations of which change from $+a$ to $-a$ when the atomic configuration is replaced by its mirror image.

It has been clearly demonstrated $[2,3]$ that optical rotation is not uniformly an additive property and that dissimilarity in configuration results in deviations from the Van't Hoff theory of optical superposition. Notwithstanding this fact, the empirical comparison of the optical rotations of related compounds, whose structures are determined by chemical methods, provides a useful means for guiding investigation in the carbohydrate field. The principle of optical superposition has been extended by Hudson [4], who observed that if the formulas for alpha and beta glucose were written as ring structures differing solely in the configuration of carbon 1, by assuming the principle of optical superposition, it is possible to obtain the value for the rotation of carbon 1 by subtracting the observed rotations of the two forms. Thus if the rotation which is due to the end asymmetric carbon be $A$, and the rotation which is due to the other four asymmetric carbons be $B$, the molecular rotation of one isomer will be $A+B$, and the molecular rotation of the other will be $-A+B$. The sum of the rotations is $2 B$ and their difference $2 A$. Like values of $2 A$ are obtained for glucose, galactose, and lactose. Hudson recognized that if this equality of rotation should exist throughout the sugar group it would offer a useful means for structural study. A comparison of the pertinent data led to the formulation of two rules. The first states that the rotation of carbon 1 is not affected by structural changes made on the other carbons; the second states that structural changes on carbon 1 do not affect the rotation of the remainder of the asymmetric sugar molecule. Although these rules of isorotation have many exceptions they have materially aided in the determination of the structures of new sugar derivatives, have been used in the classification of the various isomers, and have led to the correction of many mistakes in the literature [5]. Their application gives satisfactory values when the comparisons are made on closely related substances under strictly comparable conditions. For example, lactose, maltose, cellobiose, and gentiobiose have the glucose configuration and give rotational differences in accord with those obtained for glucose. Likewise, 4-glucosido-mannose and 4-galactosido-mannose are merely substitued mannoses and give rotational differences in agreement with those obtained for mannose [6].

In 1929 the writer [7] calculated the optical rotations for the various asymmetric carbons in the hexoses by Van't Hoff's method and pointed out that the preparation of the then unknown hexoses, talose, allose, and altrose would constitute a test for the validity of the principle as applied to these sugars. Subsequently $\alpha$ - $d$-talose $(+68.0)$ [8], $\beta$ - $d$-talose ${ }^{3}(+13.3), \beta$ - $d$-allose $(-0.2)$ [9] and $\beta$ - $d$-altrose $(-32.6)$ [10] have been prepared; the optical rotations, noted in the parentheses, are not in satisfactory agreement with the previously calculated values of $+60,-30,-60$, and -145 . It is therefore evident that the principle of optical superposition in the simple form referred to above

\footnotetext{
${ }_{2}^{2}$ Figures in brackets here and elsewhere in the text correspond to the numbered references at the end of this paper.

${ }_{3}$ The preparation and properties of this new sugar will be described in a subsequent paper by W. W. Pigman and the author.
} 
does not give concordant values for this group of configurationally different sugars. The principle, as stated by Van't Hoff, may be valid provided the asymmetric carbon is replaced by its mirror image and no other changes follow. But each atom in the molecule influences the neighboring atoms and consequently a stereomeric change results in a new distribution of atoms, electrons, and electromagnetic fields so that the conditions necessary for the valid application of the principle are not realized. The effect of changes in the configuration of neighboring groups on the optical rotation of an asymmetric carbon was noted by Rosanoff [11]. This concept has been emphasized further by Freudenberg and Kuhn [12], who point out that the configurations of atoms adjacent to a given asymmetric carbon alter its optical rotation markedly, while the configurations of the atoms separated from the given asymmetric carbon have little influence. It is therefore instructive to compare the optical rotations of the sugars, taking into account the configurations of the groups adjacent to the asymmetric centers under consideration.

TABLE 1.-Optical rotations ${ }^{1}$ of the hexoses

\begin{tabular}{|c|c|c|c|}
\hline Sugar & {$[\alpha]^{20} D$} & $\begin{array}{c}\text { Optical superposition equa- } \\
\text { tion }\end{array}$ & $\begin{array}{l}\text { Molecu- } \\
\text { lar rota- } \\
\text { tion }\end{array}$ \\
\hline 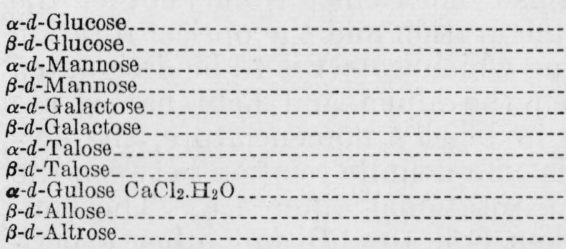 & $\begin{array}{r}+112.2 \\
+18.7 \\
+29.3 \\
-17.0 \\
+150.7 \\
+52.8 \\
+68.0 \\
+13.3 \\
+37.1 \\
-0.2 \\
+28.7\end{array}$ & $\begin{array}{l}+A_{\mathrm{oz}}+R_{2}-R_{3}+R_{4}+R_{5}= \\
-A_{\mathrm{oz}}+R_{2}-R_{3}+R_{4}+R_{5}= \\
+A_{\mathrm{oz}}-R_{2}-R_{3}+R_{4}+R_{5}= \\
-A_{\mathrm{oz}}-R_{2}-R_{3}+R_{4}+R_{5}= \\
+A_{\mathrm{or}}+R_{2}-R_{3}-R_{4}+R_{5}= \\
-A_{\mathrm{oH}}+R_{2}-R_{3}-R_{4}+R_{5}= \\
+A_{\mathrm{oH}}-R_{2}-R_{3}-R_{4}+R_{5}= \\
-A_{\mathrm{oH}}-R_{2}-R_{3}-R_{4}+R_{5}= \\
+A_{\mathrm{oH}}+R_{2}+R_{3}-R_{4}+R_{5}= \\
-A_{\mathrm{oH}}+R_{2}+R_{3}+R_{4}+R_{5}= \\
-A_{\mathrm{oH}}-R_{2}+R_{3}+R_{4}+R_{5}=\end{array}$ & $\begin{array}{r}+20,210 \\
+3,370 \\
+5,280 \\
-3,060 \\
+27,140 \\
+9,510 \\
+12,250 \\
+2,400 \\
+11,470 \\
+5,170\end{array}$ \\
\hline
\end{tabular}

1 With the exception of $\beta$ - $d$-allose and $\beta$ - $d$-altrose the optical rotations are taken from measurements by Isbell and Pigman [13]. The rotation of $\beta$ - $l$-altrose was reported by Austin and Humoller [14] to be -28.7 . As the rotation of its antipode, $\beta-d$-altrose, differs only in direction, the value +28.7 is used. The rotation of $\beta$ - $d$-allose was obtained by extrapolation of the data reported by Phelps and Bates [9].

TABLE 2.-Differences in molecular rotations

\begin{tabular}{|c|c|c|c|c|}
\hline \multicolumn{2}{|l|}{ Molecular rotations- } & \multicolumn{2}{|c|}{$\begin{array}{l}\text { Rotational } \\
\text { difference }\end{array}$} & \multirow{2}{*}{$\begin{array}{r}\begin{array}{r}\text { Configu- } \\
\text { ration of } \\
\text { adjacent } \\
\text { groups }{ }^{1}\end{array} \\
d,+ \\
d,+ \\
d, \pm \\
d,-\end{array}$} \\
\hline $\begin{array}{l}\alpha-d \text {-Glucose }-\beta-d \text {-Glucose } \\
\alpha \text {-d-Galactose- } \beta-d-\text {-Galactose } \\
\alpha \text {-d-Mannose }-\beta-d \text {-Mannose } \\
\alpha \text { - } d \text {-Talose- } \beta-d \text {-Talose }\end{array}$ & $\begin{array}{l}= \\
= \\
= \\
=\end{array}$ & $\begin{array}{l}2 A_{\text {он }} \\
2 A_{\text {он }} \\
2 A_{\text {он }} \\
2 A_{\text {он }}\end{array}$ & $\begin{array}{r}+16,840 \\
+17,630 \\
+8,340 \\
+9,850\end{array}$ & \\
\hline $\begin{array}{l}\alpha-d \text {-Glucose }-\alpha-\alpha \text {-Mannose } \\
\alpha-d \text {-Galactose }-\alpha \text { - } d \text {-Talose } \\
\beta \text { - } d \text {-Glucose }-\beta-d \text {-Mannose } \\
\beta \text { - } d \text {-Galactose }-\beta \text { - } d \text {-Talose } \\
\beta \text { - } d \text {-Allose }-\beta \text { - } d \text {-Altrose }\end{array}$ & $\begin{array}{l}= \\
= \\
= \\
=\end{array}$ & $\begin{array}{l}2 R_{2} \\
2 R_{2} \\
2 R_{2} \\
2 R_{2} \\
2 R_{2}\end{array}$ & $\begin{array}{r}+14,930 \\
+14,890 \\
+6,430 \\
+7,110 \\
-5,210\end{array}$ & $\begin{array}{l}\alpha, \overline{-} \\
\alpha, \overline{=} \\
\beta, \overline{ } \\
\beta, \overline{+}\end{array}$ \\
\hline $\begin{array}{l}\alpha \text {-d-Gulose }-\alpha-d \text {-Galactose } \\
\beta \text {-d -Allose }-\beta-d \text {-Glucose } \\
\beta \text {-d-Altrose }-\beta-d \text {-Mannose }\end{array}$ & $\begin{array}{l}= \\
= \\
=\end{array}$ & $\begin{array}{l}2 R_{3} \\
2 R_{3} \\
2 R_{3}\end{array}$ & $\begin{array}{r}-15,670 \\
-3,410 \\
+8,230\end{array}$ & $\begin{array}{l}+, \overline{+} \\
+,+ \\
-,+\end{array}$ \\
\hline $\begin{array}{l}\alpha-d \text {-Glucose- } \alpha-d \text {-Galactose } \\
\beta-d \text {-Glucose }-\beta-d \text {-Galactose } \\
\alpha-d \text {-Mannose- } \alpha-d \text {-Talose } \\
\beta-d \text {-Mannose }-\beta-d \text {-Talose }\end{array}$ & $\begin{array}{l}= \\
= \\
= \\
=\end{array}$ & $\begin{array}{l}2 R_{4} \\
2 R_{4} \\
2 R_{4} \\
2 R_{4}\end{array}$ & $\begin{array}{l}-6,930 \\
-6,140 \\
-6,970 \\
-5,460\end{array}$ & $\begin{array}{l}-,+ \\
- \pm \\
- \pm+ \\
-,+\end{array}$ \\
\hline $\begin{array}{l}\beta-d \text {-Mannose }-\alpha \text { - } l \text {-Gulose } \\
\alpha-d \text {-Talose- } \beta-l \text {-Allose } \\
\alpha-d \text {-Galactose- } \beta \text {-l-Altrose }\end{array}$ & $\begin{array}{l}= \\
= \\
=\end{array}$ & $\begin{array}{l}2 R_{5} \\
2 R_{5} \\
2 R_{5}\end{array}$ & $\begin{array}{r}+8,410 \\
+12,210 \\
+32,310\end{array}$ & $\begin{array}{l} \pm, 0 \\
\pm 0 \\
-, 0\end{array}$ \\
\hline
\end{tabular}

1 The first term of the symbol represents the configuration of the adjacent carbon which lies above the one under consideration, when the formula is written with the reducing group uppermost, while the second term represents the configuration of the carbon which lies below. 
The optical rotations of the hexose sugars are given in table 1 with equations representing their optical rotations according to the principle of optical superposition, while the optical rotations of the different asymmetric carbons, calculated algebraically, are given in table 2 . In each case the optical rotation of the asymmetric carbon, perhaps better called the rotational difference, is obtained by subtracting the equations representing the optical rotations in such a manner as to eliminate all the variables except one. In order to bring out any possible connections between the various values for the rotational differences and the configurations of the neighboring groups, the structures of the adjacent groups are indicated by symbols. The first term in the symbol represents the configuration of the adjacent carbon which lies above the one under consideration, when the formula is written with the reducing group uppermost, while the second term represents the configuration of the carbon which lies below.

The rotational difference corresponding to the first or reducing carbon has been designated $2 A_{\text {он }}$ in accord with the terminology originated by Hudson. Since the more dextrorotatory member of the alpha-beta pair is designated alpha when the oxygen ring lies to the right, it follows that subtracting the rotation of the beta sugar from the alpha must give a positive difference. Therefore, the values of $2 A_{\text {он }}$ given in table 2 are necessarily positive. If the alpha and beta names are used merely to distinguish one isomer from another the relationship between the actual configuration and the optical rotation is of little importance in determining which isomer is to be designated alpha and which beta. But when the alpha and beta names are given a structural significance, as in Isbell's nomenclature, the correctness of the assignments depends on a definite relation between the configurations and the sign of the rotational difference. The conductivity measurements of Böeseken [15, 16, 17] and other experimental data show that the hydroxyl of carbon 1 lies to the right in $\alpha$-d-glucose and $\alpha$-d-galactose when the formulas are written in the Fischer conventional manner. Therefore insofar as these compounds are concerned, the contribution of the first carbon to the optical rotation of the molecule is positive when the hydroxyl of carbon 1 lies to the right. It is generally assumed and probably true that this relationship between the configuration of the first carbon and the optical rotation applies to all pyranose sugars. Bromine oxidation measurements made with numerous sugars in the course of this investigation have shown that the alpha forms are oxidized more slowly than the beta forms; the consistent agreement of the reactivity with the names allocated from comparison of the optical rotations supports the validity of the relationship which was used for selecting the names. Hence there is a reasonable basis for the assumption that the optical rotations furnish a reliable guide for classifying the alpha and beta sugars. The classification is based on a qualitative relationship between the configuration of the first carbon and the optical rotation. The quantitative aspects of this relationship appear to be affected by other factors, particularly by the configuration of the adjacent groups. The numerical values for $2 A_{\text {он }}$ obtained from the alpha and beta modifications of glucose and galactose are 16,840 and 17,640 , while the values from the rotations of mannose and talose are 8,340 and 9,850 . The two series differ in the configurations of the adjacent groups. Unfortunately, the optical rotations of the other alpha and 
beta sugars are not known so that comparisons cannot be made directly. However, a comparison of the optical rotations of the alpha and beta methyl gulosides, glucosides, and galactosides gives values of $2 A_{\mathrm{OCH}_{3}}$ of $39,200,37,460$, and 37,900 , respectively [18]. The approximate agreement of these indicates that the rotational differences for the first carbon in the gulose series are close to those obtained for the glucose and the galactose series. Virtually no information is available for idose, altrose, and allose. The configuration of the group adjacent to the first carbon in allose resembles that of glucose, while idose and altrose resemble mannose.

The difference in the optical rotations of two sugars which differ merely in the configuration of the second carbon has been called the "epimeric difference" [19]. This difference has been used to correlate substances of like structure and probably has a legitimate application for this purpose. But the problem is complicated because there are four steric arrangements or combinations involving the configurations of the carbons adjacent to the second carbon. These are represented symbolically in the following manner: (1) $\alpha,+$; (2) $\alpha,-$; (3) $\beta$, +; (4) $\beta,-$. Epimeric pairs corresponding to the first group are not known products at present but would be represented by $\alpha$-d -gulose and $\alpha$-d-idose, or by $\alpha-d$-allose and $\alpha-d$-altrose. The second group is represented by $\alpha-d$-glucose and $\alpha-d$-mannose, and by $\alpha$ - $d$-galactose and $\alpha$ - $d$-talose. The epimeric differences obtained from these pairs, 14,930 and 14,890, are in excellent agreement. The third group is represented by $\beta$ - $d$-allose and $\beta$ - $d$-altrose. The epimeric difference for these sugars, $-5,210$, is entirely different from the others. Since these sugars have not been extensively studied it is quite possible that the optical rotations are not correct or that the sugars are improperly classified. In particular, the substance now known as $\beta$ - $d$-altrose may have the $\alpha-d$-structure. It might be noted, however, that the difference in the molecular rotations of $\beta-d$ - $\alpha$-glucoheptose and $\beta$ - $d-\beta$-glucoheptose $(-5,950)$ is in accord with that obtained for $\beta$ - $d$-allose and $\beta$ - $d$-altrose. The fourth group is represented by $\beta$ - $d$-glucose and $\beta$ - $d$-mannose, and by $\beta$ - $d$-galactose and $\beta$ - $d$-talose. The epimeric differences obtained from these pairs are 6,430 and 7,110 . The epimeric differences obtained for various configurations bring out the need for considering the configuration of adjacent groups in making comparisons and emphasize the complex character of the problem.

The rotational difference for the third carbon, obtained from $\alpha$ - $d$-gulose and $\alpha$ - $d$-galactose $(-15,670)$ deviates widely from the values $(-3,410$ and 8,230$)$ obtained from $\beta$ - $d$-allose and $\beta$ - $d$-glucose, and from $\beta$ - $d$-altrose and $\beta$ - $d$-mannose. Inasmuch as $\beta$-d-allose and $\beta$ - $d$-altrose may not have the $\beta$-pyranose structure, the comparisons may not be properly drawn.

The data available for calculating the rotational differences for the fourth carbon in the hexose series is limited to only one combination for the configurations of the adjacent carbon atoms. Four calculations from the optical rotations of eight sugars give values in approximate agreement with each other, namely, $-6,930,-6,140,-6,970$, and $-5,460$.

The determination of the optical rotation of the fifth carbon is complicated because any change in its configuration affects the adjacent ring oxygen which in turn determines the alpha and beta 
positions of the first carbon. Consequently, the rotational differences $\left(R_{5}\right)$ in table 2 include the rotation of the fifth carbon and any changes which may be induced by the difference in the alpha and beta structures. The data at hand are not sufficient to calculate the two components separately. The comparisons involving the optical rotations of allose and altrose do not appear to be in accord. This may be caused by improper classification, erroneous optical rotations, unknown structural differences, or to the physical characteristics of the phenomena of optical rotation.

The work of Tschugaeff, Kuhn, Low ry, and others [20] shows that each asymmetric carbon in an optically active substance gives rise to one or more partial rotations, which may be correlated with absorption bands of characteristic frequency which have their origin in particular electronic transitions taking place in the molecule. These transitions are not influenced greatly by atoms or groups not closely related to the asymmetric carbon. The neighboring groups, however, influence one another and thereby affect the partial rotations. The optical rotation in the visible spectrum is chiefly governed by the nearest absorption bands. Since the bands are not located at the same wave lengths for all sugars, the optical rotations for light of different wave lengths vary in irregular fashion. For this reason the difference in the rotations of two sugars depends in part on the light used for making comparison, and it is obvious that the optical rotations cannot be rigorously represented by the simple algebraic equations suggested by Van't Hoff.

Nevertheless, the active part that the principles of optical superposition and isorotation have played in the development of carbohydrate chemistry is sufficient justification for continuing their use. It has been amply demonstrated that substances of similar structure and configuration give approximately like rotational differences. In order to facilitate comparison, it is desirable to classify the sugars according to the configuration of the five asymmetric carbons which comprise the pyranose ring. The first of these carbons gives rise to the alpha and beta modifications of the separate sugars. The different configurations of carbons $2,3,4$, and 5 give the eight fundamental pyranoses from which all of the pyranose sugars may be considered to be derived. The optical rotations and other properties of the members in each group parallel one another. Hence the "rotational differences" for the members of each of the fundamental types are fairly constant and characteristic. For example, agreement is found for sugars containing the alpha mannose structure or the beta mannose, or the alpha glucose or the beta glucose, or for other configurationally related substances. But the values from configurationally different substances are frequently inconsistent. The marked resemblance of the various members of the groups represented by these types has been emphasized previously by Hudson and others and is illustrated further by the optical rotations and oxidation measurements reported in this paper.

\section{NOMENCLATURE OF THE ALPHA AND BETA SUGARS}

In order to bring out more clearly the structural relationships between the various pyranose sugars, the writer has suggested [21] certain changes in the alpha-beta nomenclature. Originally the alpha-beta names were assigned merely to distinguish one isomer 

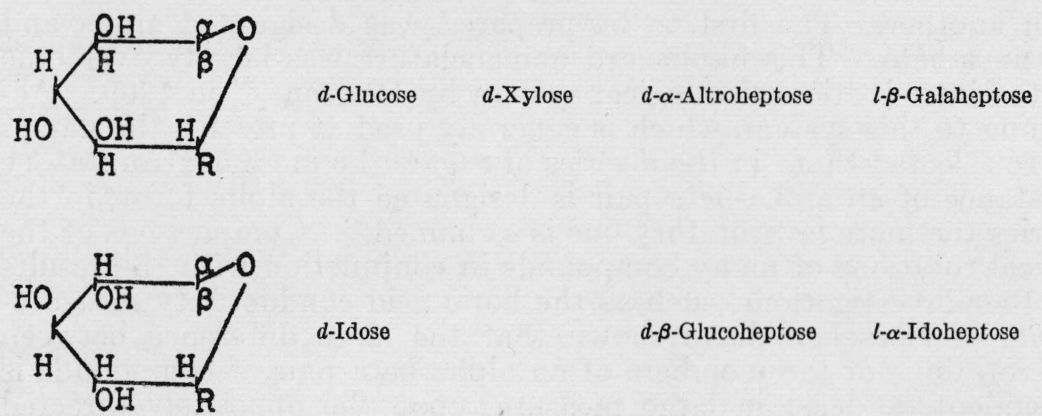

$d-\beta$-Glucoheptose $\quad l-\alpha$-Idoheptose

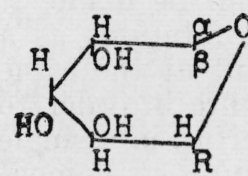

$d$-Mannose $\quad d$-Lyxose $\quad d$ - $\beta$-Altroheptose $\quad l$ - $\alpha$-Galaheptose<smiles>[R][C@H](O)C(O)O</smiles>

d-Gulose

$d$ - $\alpha$-Glucoheptose $\quad$ l- $\beta$-Idoheptose<smiles>O[C@H]1O[C@H]2O[C@@H]1[C@H](O)O2</smiles><smiles></smiles><smiles>[R]C1O[C@H](O)[C@H](O)[C@@H]1O</smiles>
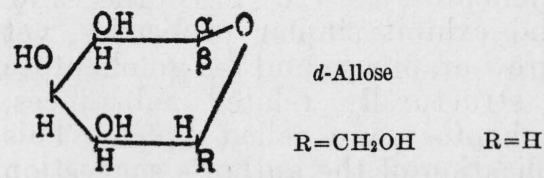

$d$ - $\alpha$-Alloheptose

l- $\beta$-Taloheptose

$\mathrm{R}=\underset{\mathrm{H}}{\mathrm{C}-\mathrm{CH}_{2} \mathrm{OH}}$

$\mathrm{R}=\underset{\mathrm{OH}}{\stackrel{\mathrm{H}}{\mathrm{C}}}-\mathrm{CH}_{2} \mathrm{OH}$

Figdre 1.-Structures for the eight pyranose types. 
from another. The first to be prepared was designated alpha and the next beta. This haphazard nomenclature was largely overcome by the introduction of a logical system by Hudson [4] in 1909. According to this system, which is generally used at present, the names are so selected that "in the $d$-series of sugars the more dextrorotatory substance of an alpha-beta pair is designated the alpha form; in the $l$-series the more levorotatory one is so named." Comparisons of the optical rotations of many compounds in conjunction with the results of other investigations, such as the boric acid conductivity measurements of Böeseken, have shown that the large difference between the rotations of the members of an alpha-beta pair of compounds is dependent, at least in large measure, upon the oppositely directed atoms or groups attached to the reducing carbon. On account of this fact and the facility with which comparisons can be made, it seems desirable to retain the comparison of optical rotations as a criterion for naming the alpha and beta sugars. But at the same time it is desirable to modify the present nomenclature in order to classify substances of like structure and similar properties in a single group. It has been recognized for a long time that Hudson's nomenclature results in classifying as beta those derivatives of $l$-arabinose which exhibit chemical and physical properties analogous to the properties of the alpha derivatives of $d$-galactose. On account of these obvious similarities various investigators have reversed the alpha and beta nomenclature for $l$-arabinose so that at present the crystalline sugar is designated by some as alpha and by others as beta.

Hudson's nomenclature depends on two factors, the $d$ and $l$ configuration of the sugar, and the optical rotation of the two isomers. According to Rosanoff's [22] $d$ and $l$ classification, substances are designated as $d$ when the hydroxyl of the terminal asymmetric carbon lies to the right when the formula is written in the conventional manner with the reducing group uppermost. If the hydroxyl on the terminal asymmetric carbon lies to the left the compound is designated $l$. Thus the antipode of $\alpha-d$-glucose is $\alpha-l$-glucose. This $d$ and $l$ classification is satisfactory and no change seems desirable. But there is no fixed relation between the $d$ and $l$ configuration and the structure of the reducing carbon. The terminal asymmetric carbon which determines the $d$ and $l$ classification may be situated outside of the pyranose ring remote from the group being named. The configuration of the terminal asymmetric carbon determines the position of the oxygen ring in the aldo-hexoses, but in the heptoses the terminal asymmetric carbon lies outside of the pyranose ring and does not have anything to do with the configuration of the first carbon. Also in the aldo-pentose and keto-hexose series the terminal asymmetric carbon is not involved in forming the oxygen ring and hence it does not have any direct bearing on the configuration of the first carbon. Crystalline $l$-arabinose $(+191), d$-galactose $(+151), d$ - $\alpha$ mannoheptose $(+120)$, and $l-\beta$-guloheptose $(+120)$ have the same structure for the pyranose ring and exhibit similar properties, yet according to Hudson's nomenclature $l$-arabinose and $l$ - $\beta$-guloheptose are designated beta, while the structurally related substances, $d$-galactose $(+151)$ and $d$ - $\alpha$-mannoheptose, are called alpha. This difficulty may be overcome by application of the author's suggestion [21] to call those isomers in which the hydroxyl of the reducing 
carbon (carbon 1 of the aldoses) lies in the same direction as the oxygen of the ring, alpha, and those in which it lies in the opposite direction, beta. This allocation is based on a structural feature and is independent of any specific reaction or property. Classification in accordance with the aforestated concept is presumably obtained by application of the following rule: The names of the members of the alpha and beta pair of sugars or sugar derivatives are so selected that when the oxygen ring lies to the right, as in $d$-glucose, the more dextrorotatory member of the alpha-beta pair shall be designated alpha, and the less dextrorotatory member beta; when the oxygen ring lies to the left, as in l-glucose (or in d-galaheptose), the less levorotatory member is called beta. This results in names for which the subtraction of the rotation of the beta form from that of the alpha gives a positive difference whenever the oxygen ring lies to the right, and a negative difference when the oxygen ring lies to the left.

To provide a convenient means for applying the rule, it is assumed that when the carbon atom, carrying the hydroxyl which originally forms the ring, is asymmetric, the oxygen of the resulting ring lies in the direction of the parent hydroxyl. This direction is ascertained by inspection of the Fischer projectional formulas. Thus the direction of the oxygen ring, as right or left, is defined in a comparative manner in the same way that the Fischer projectional formulas define the positions of the various atoms in optically active substances.

Although the carbon atom united with the ring oxygen in the aldopentoses and keto-hexoses is not asymmetric, it is tied up in the ring, forming a dissymmetric structure which resembles one and only one of the eight fundamental pyranose types. On account of this marked similarity, no difficulty is encountered in selecting appropriate names for the pentoses and other sugars in which the carbon united with the ring oxygen is not asymmetric. The resemblance of crystalline $l$-arabinose to $\alpha$ - $d$-galactose, and of $\beta$ - $l$-arabinose $\mathrm{CaCl}_{2} \cdot 4 \mathrm{H}_{2} \mathrm{O}$ to $\beta$ - $d$-galactose, and of $\alpha$ - $d$-xylose to $\alpha$ - $d$-glucose, and of $\alpha$ - and $\beta$ - $d$-lyxose to $\alpha$ - and $\beta$ - $d$-mannose has been pointed out heretofore [13], and it has been shown that the rates of oxidation support the hypothesis that these sugars are genetically related and that in each one the oxygen ring lies to the right. Hence crystalline $l$-arabinose is considered to be related in ring structure to the $d$-hexoses and its classification is made accordingly. This results in a reversal of Hudson's nomenclature for the alpha and beta derivatives of $d$ - and $l$-arabinose. Universal adoption of this change would clear up the present confusion in the nomenclature of this sugar. Structures can be assigned to the various keto-hexoses by comparison of their properties with the properties of the keto-heptoses whose structures are fixed by the asymmetry of the carbon atom united with the oxygen ring. The following Fischer projectional formulas reveal that $d$-fructose could be structurally related to $l$-galactose or to $d$-altrose. The keto-heptose analogous to $d$-altrose is $d$-altroheptulose (sedoheptose) [23], and the one analogous to $l$-galactose is $l$-galaheptulose (perselose) [24]. Sedoheptose and $d$-altrose [10] differ markedly from $d$-fructose in that they form anhydro-compounds by merely heating in acid solution. Furthermore, crystalline $d$-fructose is levorotatory and exhibits mutarotation from -133 to -92 , while sedoheptose is dextrorotatory and does not exhibit mutarotation. Perselose, on the other hand, resembles $d$-fructose in that it is levorotatory and exhibits mutarotation 
from -90 to -80 . Therefore the ring in $d$-fructose lies to the left, as in perselose, and the crystalline sugar is called $\alpha-d$-fructose. The classification of $d$-sorbose $(+42.9)$ and $d$-tagatose $(+1.0)$ is made in like manner.

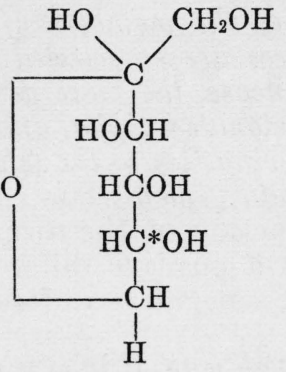

$\alpha$ - $d$-Fructose

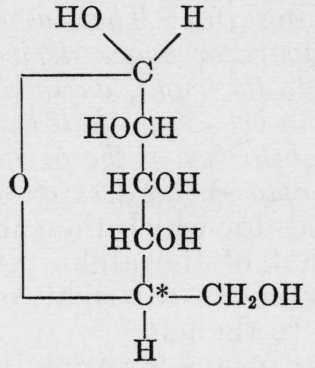

$\alpha$-l-Galactose

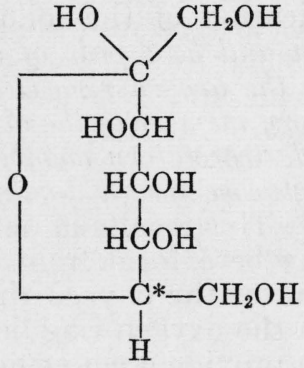

Perselose

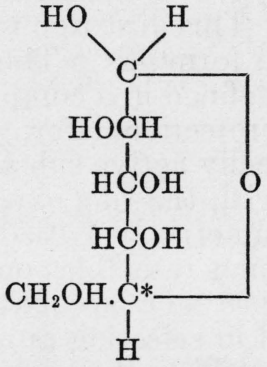

$\beta$ - $d$-Altrose

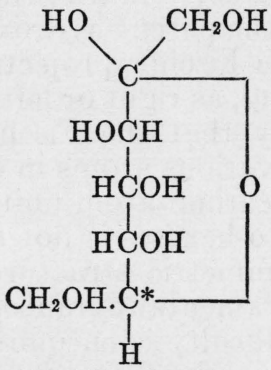

Sedoheptose

Thus $\alpha$ - $d$-sorbose $(+42.9)$ resembles $\alpha$ - $d$-glucoheptulose $(+67.4)$ and $\alpha$ - $d$-tagatose $(+1)$ resembles $\alpha-d$-mannoheptulose $(+29.37)$. A number of comparisons can be drawn between the optical rotations of fructose, sorbose, and tagatose, on the one hand, and the structurally related pentoses, hexoses, and heptoses on the other. Such comparisons have been made by Hudson [25] in the course of an investigation having a different concept but which leads to a like correlation of structurally similar sugars. Hudson's work shows that $l$-arabinose, $d$-galactose, and $l$-fructose are related structurally in the same way as $d$-xylose, $d$-glucose, and $d$-sorbose, or $d$-lyxose, $d$-mannose, and $d$-tagatose. As a final result of the above considerations it can be stated that $l$-fructose, $d$-sorbose, and $d$-tagatose are genetically related to the $d$-aldo-hexoses and that it is necessary to change the alpha and beta names for the pyranose derivatives of fructose. The soundness of this classification cannot be tested by bromine oxidation measurements, because the ketoses do not react readily with this reagent. Nevertheless, the optical rotations and other properties furnish a substantial basis for this classification.

The changes in nomenclature which have been suggested will alter the names of those substances in which the configuration of the carbon forming the oxygen ring differs from the configuration of the terminal asymmetric carbon. Thus the names will be reversed for the isomeric sugars and derivatives of arabinose, fructose, and the galabeptoses, 
guloheptoses, taloheptoses, and idoheptoses. The changes in the present system of naming the alpha and beta sugars have been advanced in order to eliminate some of the obvious shortcomings of the present system. An attempt has been made to group substances having like pyranose rings, regardless of what may be the configuration of the groups in the appendage. It is recognized that no simple nomenclature will account for all properties because each group in the molecule influences the others and produces characteristic properties.

\section{MUTAROTATIONS OF THE HEPTOSES AND THE STRUCTURALLY RELATED HEXOSES}

In order to prove that the configuration of the fifth carbon in the aldoses determines the direction of the oxygen ring and that a more satisfactory classification of the alpha and beta sugars is obtained by basing the nomenclature on the configuration of the fifth carbon, rather than on the $d$ and $l$ configurational series, the writer has synthesized and studied the properties of a number of heptose sugars which are pertinent to this subject. These sugars were prepared from the corresponding hexoses by the cyanhydrin synthesis [26]. The methods used for their preparation are described in the literature and will not be reviewed in this paper. The intermediate products and the crystalline sugars, however, were separated without seed from other sources and with relatively little difficulty.

Characteristic and important variations in the mutarotations of the sugars are indicative of the changes and reactions of the first carbon, and, therefore, it is of interest to compare the mutarotations of the heptoses and hexoses in order to bring out similar characteristics which may be used for the correlation of substances of like structure. It was shown by Smith and Lowry [27] that the optical rotation of a freshly prepared solution of $\alpha$ - $d$-galactose changes rapidly at first, decreasing in a few minutes to a uniform rate; while the optical rotation of a freshly prepared solution of $\beta$ - $d$-galactose changes slowly at first, increasing in a few minutes to the rate characteristic of the latter part of the mutarotation of the alpha modification. Similar changes are also exhibited by $\alpha$ - and $\beta$-l-arabinose. As two of the heptoses have the galactose structure for the pyranose ring, it is of interest to determine whether they give like mutarotation curves, and if so, to ascertain which of the modifications corresponds to $\alpha$ - $d$-galactose and which to $\beta$ - $d$-galactose.

The mutarotations of $\alpha$ - $d$-galactose, $\alpha-l$-arabinose, $\alpha$ - $d$ - $\alpha$-mannoheptose, and $\alpha-d-\beta$-guloheptose are illustrated by the curves of figure 2 , while the mutarotations of $\beta$ - $d$-galactose, $\beta$ - $l$-arabinose $\mathrm{CaCl}_{2} \cdot 4 \mathrm{H}_{2} \mathrm{O}$, and $\beta$ - $d$ - $\alpha$-mannoheptose are illustrated in figure 3 . The curves for $\alpha$ - and $\beta$ - $d$-galactose and $l$-arabinose are based on the measurements reported recently [13], while those for $\alpha$ - and $\beta-d-\alpha-$ mannoheptose and $\alpha-d-\beta$-guloheptose are based on the data in table 3. As the rotational differences are plotted on a semilogarithmic scale, the deviations from the simple monomolecular course is represented by the divergence of the rotational curve from a straight line. Since the mutarotations of the pentoses take place much more rapidly than the mutarotations of the hexoses and heptoses, the curves are drawn on different time scales, as indicated at the bottom of the figure. The curves show that the optical rotations of the alpha modifications 
change more rapidly at first, decreasing in a few minutes to a uniform rate. This is characteristic of the $\alpha$ - $d$-galactose structure. The optical rotations of the beta isomers, however, change slowly at first,

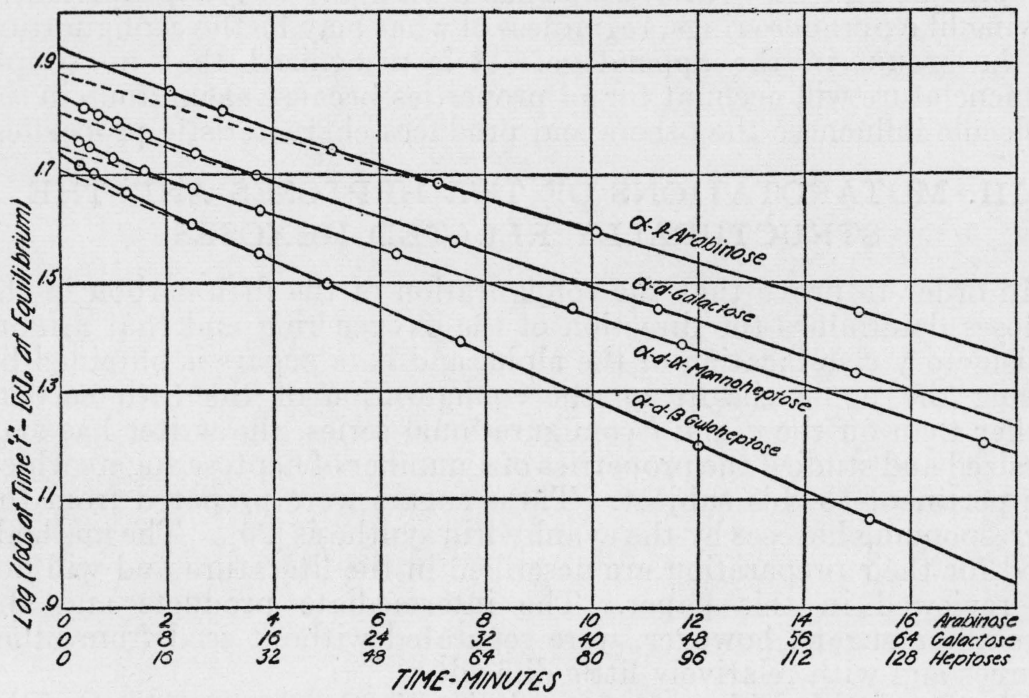

FIGURe 2.-Mutarotations of sugars related to a-d-galactose.

increasing in a few minutes to a uniform rate. The striking similarity of the mutarotation curves obtained for the members of the first group, on the one hand, and for the members of the second group on

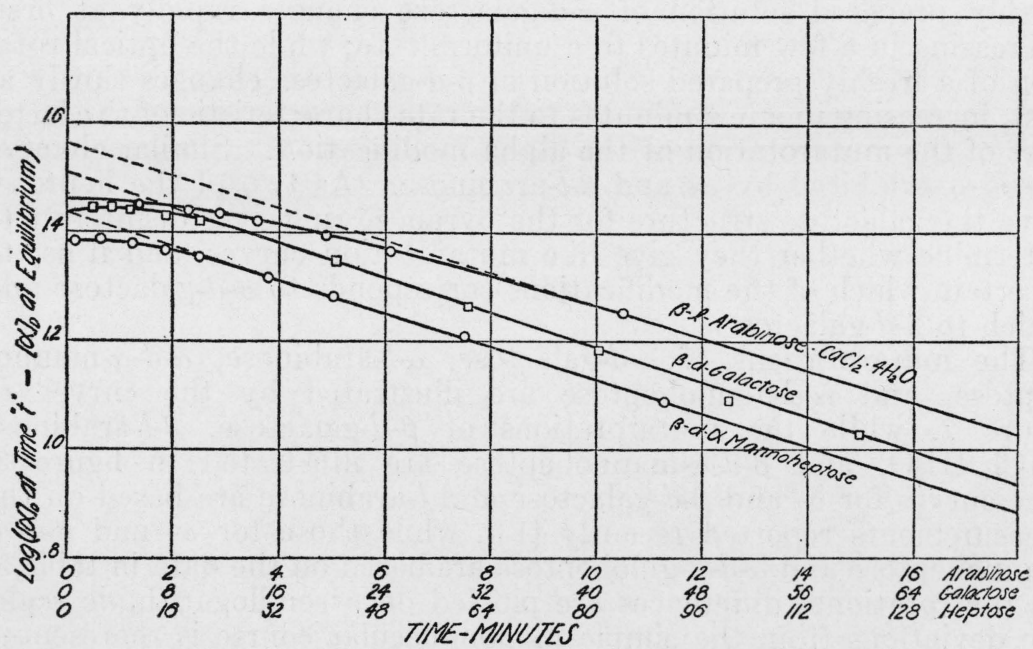

FIGURE 3.-Mutarotations of sugars related to $\beta$-d-galactose.

the other, supports the nomenclature which designates the members of the first group as alpha, and the members of the second group as beta. 
TABLE 3.-Complex mutarotations of sugars in water ${ }^{1}$ $a-d-a-M A N N O H E P T O S E$ (HYDRATE)

$3.5 \mathrm{~g}$ per $100 \mathrm{ml}$ at $20^{\circ} \mathrm{C}$ read in a $4-\mathrm{dm}$ tube. ${ }^{\circ} \mathrm{S}=1.37 \times 10^{-.0485 t}+21.12 \times 10^{-.00391 t}+26.33$ $[a]^{20} D=3.4 \times 10^{-.0485 t}+51.9 \times 10^{-.00301 t}+64.7$.

\begin{tabular}{|c|c|c|c|c|c|}
\hline Time & $\begin{array}{l}\text { Observed } \\
\text { reading }\end{array}$ & $\left(k_{1}+k\right)_{2} \times 10^{3}$ & $m_{1} \times 10^{3}$ & Deviation & $m_{2} \times 10^{3}$ \\
\hline Minutes & ${ }^{\circ} \mathrm{S}$ & & & & \\
\hline $\begin{array}{l}2.89 \\
4.48 \\
5.88 \\
8.20\end{array}$ & $\begin{array}{r}+47.90 \\
+47.42 \\
+47.11 \\
+46.47\end{array}$ & $\begin{array}{l}6.14 \\
5.42 \\
5.61\end{array}$ & - & $\begin{array}{r}+1.87 \\
+0.99 \\
+.81 \\
+.75 \\
+.52\end{array}$ & $\begin{array}{c}(54.8) \\
40.3 \\
52.7\end{array}$ \\
\hline $\begin{array}{l}10.31 \\
12.81 \\
15.36 \\
20.02 \\
25.10\end{array}$ & $\begin{array}{l}+46.02 \\
+45.44 \\
+44.97 \\
+44.08 \\
+43.21\end{array}$ & $\begin{array}{l}5.34 \\
5.30 \\
5.08 \\
4.94 \\
4.79\end{array}$ & - & $\begin{array}{l}+.44 \\
+.29 \\
+.25 \\
+.11 \\
+.03\end{array}$ & $\begin{array}{c}47.5 \\
53.8 \\
47.9 \\
(55.7) \\
\end{array}$ \\
\hline $\begin{array}{l}30.28 \\
40.37 \\
50.47 \\
60.93 \\
77.11\end{array}$ & $\begin{array}{l}+42.41 \\
+41.02 \\
+39.72 \\
+38.57 \\
+36.92\end{array}$ & $\begin{array}{l}4.66 \\
4.45 \\
4.35 \\
4.24 \\
4.16\end{array}$ & $\begin{array}{l}3.89 \\
3.93 \\
3.87 \\
3.87\end{array}$ & - & 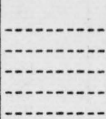 \\
\hline $\begin{array}{r}93.55 \\
139.08 \\
190.38 \\
290.14 \\
\infty\end{array}$ & $\begin{array}{l}+35.46 \\
+32.30 \\
+30.06 \\
+27.85 \\
+26.33\end{array}$ & $\begin{array}{r}4.12 \\
4.10 \\
4.06 \\
4.01 \\
\end{array}$ & $\begin{array}{r}3.89 \\
3.96 \\
3.96 \\
3.94 \\
\end{array}$ & 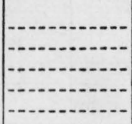 & 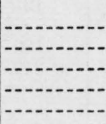 \\
\hline A verage... & - & - & 3.91 & - & 48.5 \\
\hline
\end{tabular}

$\boldsymbol{\beta}-\boldsymbol{d}$ - $a$-MANNOHEPTOSE (HYDRATE)

$4 \mathrm{~g}$ per $100 \mathrm{ml}$ at $20^{\circ} \mathrm{C}$ read in a 4 -dm tube. $[a]{ }^{20} D=2.9 \times 10^{-.048 t}-25.1 \times 10^{-.00334 t}+64.5$.

\begin{tabular}{|c|c|c|c|c|c|}
\hline Time & $\begin{array}{l}\text { Observed } \\
\text { reading }\end{array}$ & $\left(k_{1}+k_{2}\right) \times 10^{3}$ & $m_{1} \times 10^{3}$ & Deviation & $m_{3} \times 10^{3}$ \\
\hline Minutes & ${ }^{\circ} \mathrm{S}$ & & & ${ }^{\circ} \mathrm{S}$ & \\
\hline $\begin{array}{l}1.20 \\
2.25 \\
5.18 \\
9.96\end{array}$ & $\begin{array}{r}+20.25 \\
+20.24 \\
+20.23 \\
+20.37\end{array}$ & $\begin{array}{l}0.00 \\
.00 \\
.56\end{array}$ & 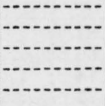 & $\begin{array}{r}+1.23 \\
+1.11 \\
+0.80 \\
+.47\end{array}$ & $\begin{array}{c}(42.5) \\
46.9 \\
47.7\end{array}$ \\
\hline $\begin{array}{l}15.02 \\
20.05 \\
24.89 \\
30.37 \\
40.17\end{array}$ & $\begin{array}{l}+20.65 \\
+20.98 \\
+21.35 \\
+21.76 \\
+22.48\end{array}$ & $\begin{array}{l}\text { 1. } 20 \\
1.64 \\
2.00 \\
2.28 \\
2.62\end{array}$ & - & $\begin{array}{l}+.27 \\
+.14 \\
+.09 \\
+.04\end{array}$ & $\begin{array}{c}47.6 \\
50.1 \\
47.9 \\
(51.0)\end{array}$ \\
\hline $\begin{array}{r}50.26 \\
60.00 \\
90.17 \\
150.09 \\
212.51\end{array}$ & $\begin{array}{l}+23.20 \\
+23.84 \\
+25.51 \\
+27.72 \\
+29.05\end{array}$ & $\begin{array}{l}\text { 2. } 87 \\
\text { 3. } 04 \\
\text { 3. } 33 \\
\text { 3. } 53 \\
\text { 3. } 61\end{array}$ & $\begin{array}{l}3.86 \\
3.86 \\
3.88 \\
3.84 \\
3.83\end{array}$ & 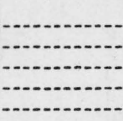 & 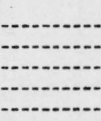 \\
\hline $\begin{array}{l}271.0 \\
441.5 \\
\infty\end{array}$ & $\begin{array}{r}+29.78 \\
+30.64 \\
+30.89 \\
\end{array}$ & $\begin{array}{l}3.64 \\
3.70\end{array}$ & $\begin{array}{l}3.81 \\
3.80\end{array}$ & & 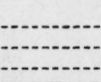 \\
\hline A verage. & & & 3. 84 & & 48.0 \\
\hline
\end{tabular}

1 The equations and values for $m_{1}$ and $m_{2}$ are determined by the method described by Isbell and Pigman, J. Research NBS 18, 156 (1937) RP969. 
TABLE 3.-Complex mutarotations of sugars in water-Continued $\boldsymbol{\alpha}-d-\beta$-GULOHEPTOSE

$4 \mathrm{~g}$ per $100 \mathrm{ml}$ at $20^{\circ} \mathrm{O}$ read in a $4-\mathrm{dm}$ tube

${ }^{\circ} \mathrm{S}=-24.06 \times 10^{-.00533 t}-1.81 \times 10^{-.0507 t}-30.44$

$[\alpha] D^{20}=-51.5 \times 10^{-.00533 t-3.9 \times 10^{-.0597 t}-65.1}$

\begin{tabular}{|c|c|c|c|c|c|}
\hline Time & $\begin{array}{l}\text { Observed } \\
\text { reading }\end{array}$ & $\left(\mathrm{k}_{1}+\mathrm{k}_{2}\right) \times 10^{3}$ & $\mathrm{~m}_{1} \times 10^{3}$ & Deviation & $\mathrm{m}_{2} \times 10^{3}$ \\
\hline \multirow{3}{*}{$\begin{array}{c}\text { Minutes } \\
0 \\
3.13 \\
5.09 \\
7.84 \\
9.95\end{array}$} & ${ }^{\circ} \mathrm{S}$ & & & \multirow{3}{*}{$\begin{array}{l}{ }^{\circ} \mathrm{S} \\
-1.81 \\
-1.18 \\
-.90 \\
-.65 \\
-.49\end{array}$} & \\
\hline & -54.77 & & & & $\cdots$ \\
\hline & $\begin{array}{l}-53.94 \\
-52.94 \\
-52.22\end{array}$ & $\begin{array}{l}7.68 \\
7.21 \\
7.05\end{array}$ & - & & $\begin{array}{l}60.1 \\
55.0 \\
56.0\end{array}$ \\
\hline \multirow{2}{*}{$\begin{array}{l}14.92 \\
19.89 \\
24.89 \\
29.94 \\
39.98\end{array}$} & $\begin{array}{l}-50.69 \\
-49.39 \\
-48.18\end{array}$ & $\begin{array}{l}6.76 \\
6.48 \\
6.40\end{array}$ & & $\begin{array}{r}-.21 \\
-.10 \\
-(.01)\end{array}$ & $\begin{array}{l}63.6 \\
64.0\end{array}$ \\
\hline & $\begin{array}{l}-47.10 \\
-45.22\end{array}$ & $\begin{array}{l}6.13 \\
5.87\end{array}$ & & & \\
\hline \multirow{4}{*}{$\begin{array}{r}50.27 \\
60.18 \\
75.08 \\
96.01 \\
121.89\end{array}$} & -43.45 & 5. 77 & 5. 28 & & \\
\hline & -41.93 & 5.71 & 5. 34 & & \\
\hline & -37.84 & 5.57 & 5.33 & -...- & \\
\hline & -35.87 & 5.48 & 5.29 & & \\
\hline \multirow{2}{*}{$\begin{array}{c}180.08 \\
250.97 \\
\infty\end{array}$} & -33.06 & 5.47 & 5. 35 & & \\
\hline & $\begin{array}{l}-31.45 \\
-30.44\end{array}$ & 5. 58 & & & \\
\hline Average... & & & 5.33 & & 59.7 \\
\hline
\end{tabular}

$\boldsymbol{\beta}-\boldsymbol{d}-\boldsymbol{\beta}$-GLUCOHEPTOSE

$5 \mathrm{~g}$ per $100 \mathrm{ml}$ at $20^{\circ} \mathrm{C}$ read in a $4-\mathrm{dm}$ tube

${ }^{\circ} \mathrm{S}=+6.5 \times 10^{-.050 t}-6.5 \times 10-.0108 t-0.08$

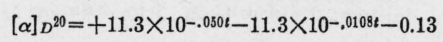

\begin{tabular}{|c|c|c|c|c|c|}
\hline Time & $\begin{array}{l}\text { Observed } \\
\text { reading }\end{array}$ & $\left(k_{1}+k_{2}\right) \times 10^{3}$ & $m_{1} \times 10^{3}$ & Deviation & $m_{2} \times 10^{3}$ \\
\hline $\begin{array}{c}\text { Minutes } \\
0 \\
1.3 \\
3.2 \\
5.1 \\
7.5\end{array}$ & $\begin{array}{c}{ }^{\circ} \mathrm{S} \\
-0.81 \\
-1.56 \\
-2.14 \\
-2.72\end{array}$ & 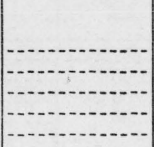 & 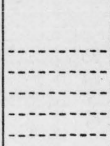 & $\begin{array}{l}{ }^{\circ} \mathrm{S} \\
(+6.53) \\
+5.57 \\
+4.53 \\
+3.67 \\
+2.77\end{array}$ & $\begin{array}{l}49.6 \\
48.9 \\
49.7\end{array}$ \\
\hline $\begin{array}{l}10.0 \\
15.0 \\
18.0 \\
20.0 \\
30.0\end{array}$ & $\begin{array}{l}-3.00 \\
-3.35 \\
-3.43 \\
-3.41 \\
-3.00\end{array}$ & 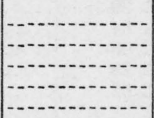 & 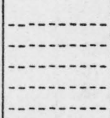 & $\begin{array}{r}+2.15 \\
+1.21 \\
+.81 \\
+.63 \\
\end{array}$ & $\begin{array}{r}48.3 \\
48.7 \\
50.3 \\
50.7 \\
\end{array}$ \\
\hline $\begin{array}{l}40.0 \\
50.0 \\
60.0 \\
70.0 \\
80.0\end{array}$ & $\begin{array}{r}-2.48 \\
-1.96 \\
-1.56 \\
-1.21 \\
-.92\end{array}$ & 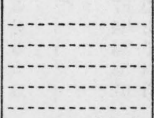 & $\begin{array}{l}10.6 \\
10.5 \\
10.8 \\
11.3\end{array}$ & 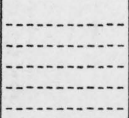 & 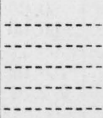 \\
\hline $\begin{array}{r}90.0 \\
100.0 \\
120.0 \\
\infty\end{array}$ & $\begin{array}{l}-.75 \\
-.64 \\
-.40 \\
-.08\end{array}$ & 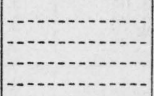 & $\begin{array}{c}11.0 \\
10.6 \\
10.8 \\
\end{array}$ & 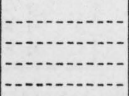 & - \\
\hline Average. & 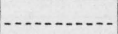 & $\ldots$ & 10.8 & $\ldots$ & 49.5 \\
\hline
\end{tabular}


TABLE 4.-First-order mutarotations $\alpha-d-\alpha$-GALACTOHEPTOSE (HYDRATE)

$4 \mathrm{~g}$ per $100 \mathrm{ml}$ at $20^{\circ} \mathrm{C}$ read in a $4-\mathrm{dm}$ tube.

${ }^{\circ} \mathrm{S}=-5.19 \times 10^{-.00471 t}-6.48$

$[\alpha]_{D}^{20}=-11.2 \times 10^{-.00471 t-14.0}$

\begin{tabular}{|c|c|c|c|c|c|}
\hline Time & $\begin{array}{l}\text { Observed } \\
\text { reading }\end{array}$ & $\left(k_{1}+k_{2}\right) \times 10^{3}$ & $\operatorname{Tim} \theta$ & $\begin{array}{l}\text { Observed } \\
\text { reading }\end{array}$ & $\left(k_{1}+k_{2}\right) \times 10^{3}$ \\
\hline \multirow[t]{2}{*}{$\begin{array}{c}\text { Minutes } \\
1.77 \\
3.55 \\
10.35 \\
15.07 \\
19.93 \\
25.04 \\
30.77 \\
45.61\end{array}$} & \multirow[t]{2}{*}{$\begin{array}{c}{ }^{\circ} \mathrm{S} \\
-11.57 \\
-11.49 \\
-11.14 \\
-10.91 \\
-10.66 \\
-10.42 \\
-10.18 \\
-9.61\end{array}$} & \multirow[t]{2}{*}{$\begin{array}{l}(3.88) \\
4.46 \\
4.53 \\
4.71 \\
4.78 \\
4.78 \\
4.82\end{array}$} & \multirow[t]{2}{*}{$\begin{array}{c}\text { Minutes } \\
60.12 \\
90.17 \\
121.6 \\
255.2 \\
393.0 \\
\infty \\
\text { Average...- }\end{array}$} & $\begin{array}{l}{ }^{\circ} \mathrm{S} \\
-9.13 \\
-8.39 \\
-7.82 \\
-6.86 \\
-6.55 \\
-6.48 \\
\end{array}$ & $\begin{array}{c}4.86 \\
4.82 \\
4.84 \\
4.45 \\
4.76 \\
\end{array}$ \\
\hline & & & & & 4. 71 \\
\hline
\end{tabular}

\section{$\beta-d-\alpha$-GLUCOHEPTOSE}

$4 \mathrm{~g}$ per $100 \mathrm{ml}$ at $20^{\circ} \mathrm{C}$ read in a $4-\mathrm{dm}$ tube.

${ }^{\circ} \mathrm{S}=-3.90 \times 10^{-.0080 t-9.28}$

$[\alpha]_{D}^{20}=-8.5 \times 10^{-.0080 t}-20.2$

\begin{tabular}{|c|c|c|c|c|c|}
\hline Time & $\begin{array}{l}\text { Observed } \\
\text { reading }\end{array}$ & $\left(k_{1}+k_{2}\right) \times 10^{3}$ & Time & $\begin{array}{l}\text { Observed } \\
\text { reading }\end{array}$ & $\left(k_{1}+k_{2}\right) \times 10^{3}$ \\
\hline \multirow[t]{2}{*}{$\begin{array}{c}\text { Minutes } \\
3.59 \\
5.04 \\
9.85 \\
15.16 \\
20.06 \\
25.23 \\
29.99\end{array}$} & \multirow[t]{2}{*}{$\begin{array}{c}{ }^{\circ} \mathrm{S} \\
-12.93 \\
-12.78 \\
-12.54 \\
-12.27 \\
-12.02 \\
-11.79 \\
-11.55\end{array}$} & \multirow[t]{2}{*}{$\begin{array}{c}(12.57) \\
7.84 \\
7.49 \\
7.56 \\
7.51 \\
7.81\end{array}$} & $\begin{array}{r}\text { Minutes } \\
47.55 \\
60.19 \\
79.18 \\
91.03 \\
121.94 \\
\infty\end{array}$ & $\begin{array}{l}\circ \mathrm{g} \\
-10.88 \\
-10.54 \\
-10.12 \\
-9.99 \\
-9.62 \\
-9.28 \\
\end{array}$ & $\begin{array}{r}8.15 \\
8.16 \\
8.44 \\
8.13 \\
8.71 \\
\end{array}$ \\
\hline & & & Average & & 7.98 \\
\hline
\end{tabular}

$\beta$ - $d$ - $\beta$-GALAHEPTOSE

$4 \mathrm{~g}$ per $100 \mathrm{ml}$ at $20^{\circ} \mathrm{C}$ read in a 4-dm tube.

${ }^{\circ} \mathrm{S}=16.05 \times 10^{-.00107 t}-24.89$

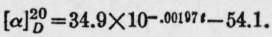

\begin{tabular}{|c|c|c|c|c|c|}
\hline $\operatorname{Tim} \theta$ & $\begin{array}{c}\text { Observed } \\
\text { reading }\end{array}$ & $\left(k_{1}+k_{2}\right) \times 10^{3}$ & $\operatorname{Tim} \theta$ & $\begin{array}{l}\text { Observed } \\
\text { reading }\end{array}$ & $\left(k_{1}+k_{2}\right) \times 10^{3}$ \\
\hline \multirow[t]{2}{*}{$\begin{array}{c}\text { Minutes } \\
4.54 \\
8.08 \\
11.29 \\
14.80 \\
19.93 \\
30.40 \\
39.94 \\
61.36\end{array}$} & \multirow[t]{2}{*}{$\begin{array}{c}{ }^{\circ} \mathrm{S} \\
-9.15 \\
-9.39 \\
-9.65 \\
-9.91 \\
-10.17 \\
-10.87 \\
-11.45 \\
-12.71\end{array}$} & \multirow[t]{2}{*}{$\begin{array}{l}1.88 \\
2.08 \\
2.09 \\
1.89 \\
1.94 \\
1.94 \\
1.96\end{array}$} & \multirow[t]{2}{*}{$\begin{array}{r}\text { Minutes } \\
90.24 \\
120.02 \\
179.96 \\
264.79 \\
329.25 \\
415.00 \\
\infty\end{array}$} & $\begin{array}{c}\circ \mathrm{S} \\
-14.24 \\
-15.54 \\
-17.85 \\
-20.10 \\
-21.24 \\
-22.37 \\
-24.89 \\
\end{array}$ & $\begin{array}{r}1.98 \\
1.96 \\
1.99 \\
1.99 \\
1.95 \\
1.94 \\
\end{array}$ \\
\hline & & & & & 1.97 \\
\hline
\end{tabular}


TABLE 5.-Optical rotations of related sugars

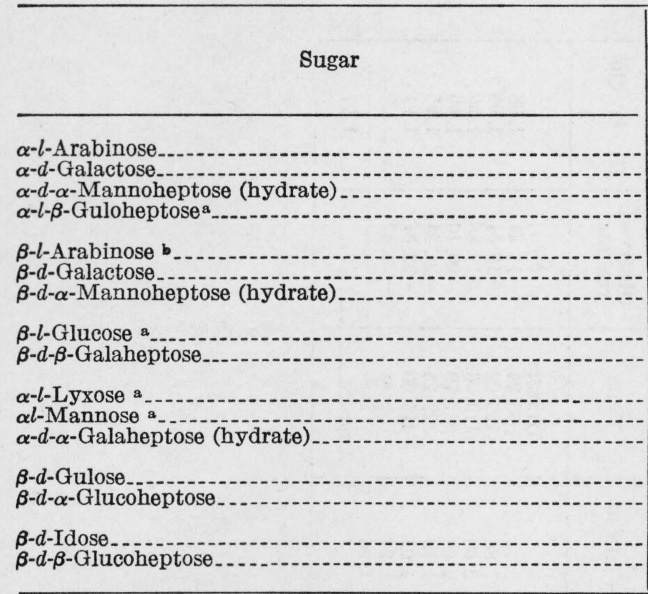

\begin{tabular}{|c|c|c|c|}
\hline $\begin{array}{l}\text { Initial } \\
{[\alpha]_{D}^{20}}\end{array}$ & $\begin{array}{l}\text { Equilibrium } \\
\qquad[\alpha]_{D}^{20}\end{array}$ & {$[\alpha]_{D}^{20}$ at $t$ minutes after dissolving crystals } & $\begin{array}{l}\text { Molecular } \\
\text { rotation } \\
{[M]}\end{array}$ \\
\hline $\begin{array}{l}+190.6 \\
+150.7 \\
+120.0 \\
+120.5\end{array}$ & $\begin{array}{r}+104.5 \\
+80.2 \\
+64.7 \\
+65.1\end{array}$ & $\begin{array}{l}+8.8 \times 10^{-.138 t}+77.3 \times 10^{-} .030 t+104.5 \\
+5.6 \times 10^{-.0700}+64.9 \times 10^{-} .00803 t+80.2 \\
+3.4 \times 10^{-} .0485 t+51.9 \times 10^{-} .00031 t+64.7 \\
+3.9 \times 10^{-.0507 t}+51.5 \times 10^{-} .00533 t+65.1\end{array}$ & $\begin{array}{l}+28,610 \\
+27,150 \\
+27,380 \\
+25,320\end{array}$ \\
\hline $\begin{array}{l}+75.5 \\
+52.8 \\
+42.3\end{array}$ & $\begin{array}{r}+104.5 \\
+80.2 \\
+64.5\end{array}$ & 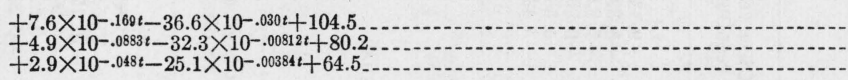 & $\begin{array}{r}+11,560 \\
+9,510 \\
+9,650\end{array}$ \\
\hline $\begin{array}{l}-18.7 \\
-19.2\end{array}$ & $\begin{array}{l}-52.7 \\
-54.1\end{array}$ & $\begin{array}{l}+34.0 \times 10-.00625 t-52.7 \\
+34.9 \times 10-.00107 t-54.1\end{array}$ & $\begin{array}{l}-3,370 \\
-4,030\end{array}$ \\
\hline $\begin{array}{r}-5.6 \\
-29.3 \\
-25.2\end{array}$ & $\begin{array}{l}+13.8 \\
-14.2 \\
-14.0\end{array}$ & $\begin{array}{l}-19.4 \times 10^{-} .0568 t+13.8 \\
-15.1 \times 10^{-0.173 t-14.2} \\
-11.2 \times 10^{-0} .0471 t-14.0\end{array}$ & $\begin{array}{r}-860 \\
-5,280 \\
-5,750\end{array}$ \\
\hline $\begin{array}{l}(0) \\
-28.7\end{array}$ & $\begin{array}{l}-26.4 \\
-20.2\end{array}$ & $-8.5 \times 10^{-} .0080 t-20.2$ & $-4,240$ \\
\hline$\stackrel{(0)}{-0.1}$ & (o) -0.1 & $+11.3 \times 10^{-} .050 t-11.3 \times 10^{-.0108 t}-0.1 \ldots$ & -40 \\
\hline
\end{tabular}

a Data from results obtained with the optical antipode.

Data from the calcium chloride compound.

Unknown. 
As may be observed from the data given in table 4, the mutarotation of $\alpha-d$ - $\alpha$-galaheptose follows, within the experimental error, the unimolecular course and gives a constant value of 0.0047 for $k_{1}+k_{2}$. This is not in accord with the observations of Hann, Merrill, and Hudson [28] who report a drift in the velocity constant from 0.032 to 0.016 . The mutarotation of $\beta-d-\beta$-galaheptose is in essential agreement with that reported recently by Hann and Hudson [46] except that it is slightly slower. The mutarotation of $\beta-d-\alpha$-glucoheptose was also found to take place at a slower rate $\left(k_{1}+k_{2}=0.008\right)$ than that (0.0122) reported by Hudson and Yanovsky [29]. The mutarotations of the sugars having the glucose, mannose, and gulose structures follow the unimolecular formula, while the mutarotations of the heptoses having the galactose and idose structures do not follow the unimolecular course and require for expression equations containing two exponential terms. The striking similarity of substances with like configurations for the carbons comprising the pyranose ring clearly indicates that the members of such groups have like structures. The complex mutarotations may arise from the formation of the free aldehyde or furanose modifications in the equilibrium solution or from the interconversion of two or more strainless ring isomers.

\section{CONFORMATION OF THE PYRANOSE RING}

It was pointed out by Haworth [30] that various geometric forms are possible for the pyranose ring. Thus if the carbon and oxygen atoms comprising the ring were coplanar the valence angles would be larger than $109^{\circ}$, required to give a strainless ring; if the ring is strainless the valence angles for the carbon atoms will be about $109^{\circ}$ and the carbon and the oxygen atoms cannot lie in a single plane. As measurements of dipole moments for simple substances containing the pyranose ring reveal that the oxygen valence bonds form an angle considerably less than $109^{\circ}$, it seems probable that the pyranose ring is bent or puckered [31, 32]. Although ten or more strainless ring structures are possible [33] they can be reduced to three types, as represented in fig. 4: (I) a trans structure in which four atoms lie in one plane, and the two remaining atoms lie on opposite sides of this plane; (II) a cis or boat-shaped structure in which 2 atoms lie on the same side of the plane formed by the four remaining atoms; (III) and (IV) structures in which the carbon atoms are coplanar and the ring-oxygen is not in the same plane. The monoplanar strained model is represented by $(\mathrm{V})$.

The X-ray investigations of Cox [32] and others indicate that the carbon atoms forming the ring in many sugars are coplanar, while the ring-oxygen lies outside the plane of the carbon atoms. Two structures of this character are possible for each hexose; in one of these the sixth carbon lies approximately in the plane of the carbon ring, as in (III); in the other it lies opposite the ring-oxygen, directed towards the first carbon as in (IV). At this time there is not a satisfactory chemical method for deciding which models correspond to the free sugars. Several sugar derivatives exist which for stereomeric reasons are limited to certain models. Thus trimethyl 1,4-anhydroglucopyranose [34] requires the conformation of a boat-shaped ring in which carbons 1 and 4 lie in the trough. The model which will serve for this compound, however, will not serve for 2,3-4,6-diacetone $\alpha$-methyl mannopyranoside [35], because in order to form a 1,4- 
anhydro derivative the hydroxyl on carbon 4 (which is the same for mannose and glucose) must be directed towards carbon 1 which is in opposition to carbon 6 . It is thus apparent that the conformation of the pyranose ring is not the same for all sugar derivatives. It is possible that the various modifications exist in dynamic equilibrium. Consequently the particular modification which results after condensation with a second group is not necessarily the same modification
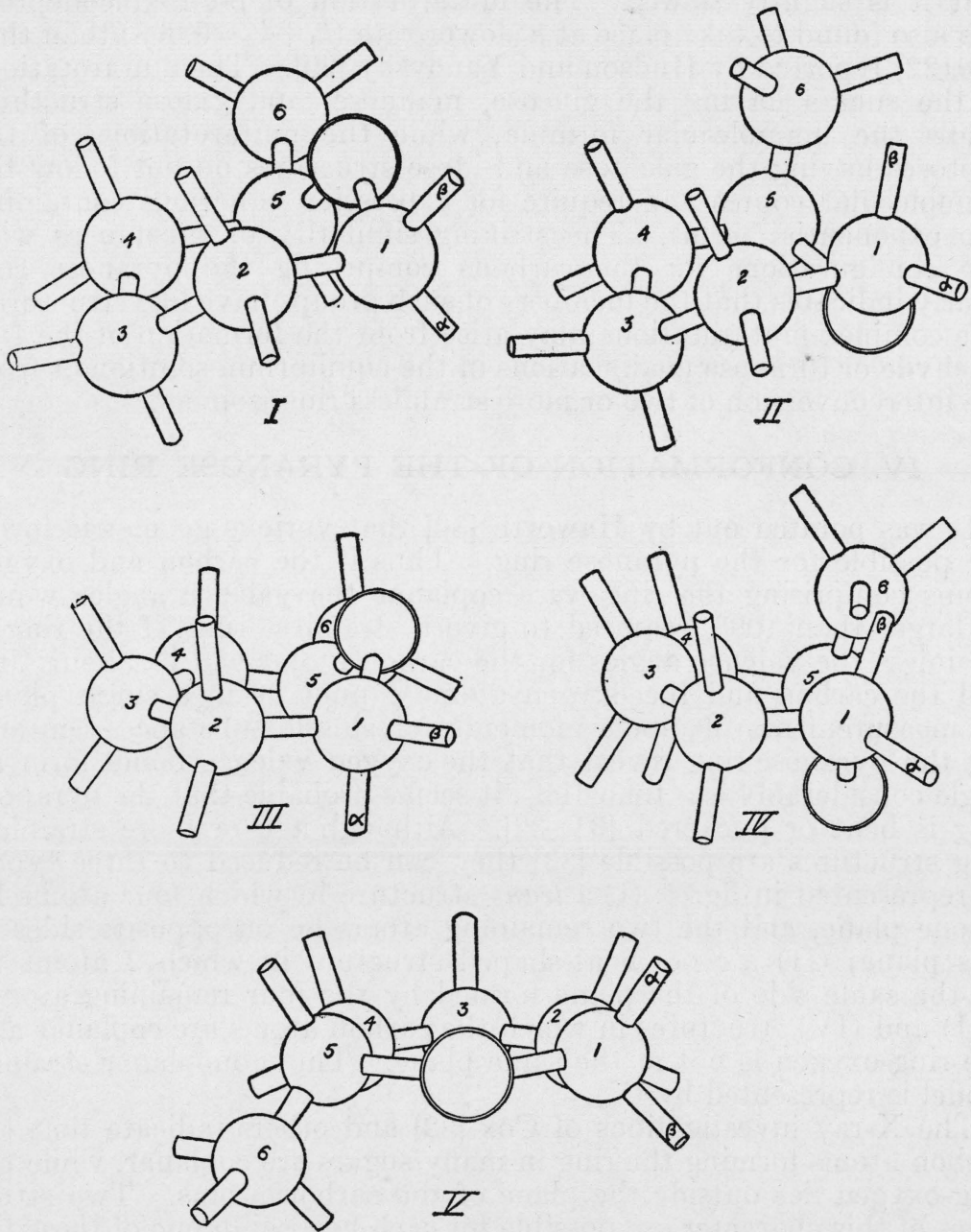

Figure 4.-Models for the pyranose ring.

as that of the original sugar. It seems probable, however, that structurally related substances such as $\alpha-l$-arabinose, $\alpha-d$-galactose, $\alpha$ - $d$-fucose, $\alpha$-l-fructose, $\alpha-d$ - $\alpha$-mannoheptose, etc., have similar ring conformations. It can be observed from models (III) and (IV), illustrated in figure 4, that the ring-oxygen might be directed to either side of the plane of the carbon atoms. But since no more than two isomers of any one ring type are known, it seems probable that each free sugar occurs in only one ring conformation. The separate sugars, however, may have different conformations. 
If the sugars had the coplanar ring, the alpha and beta positions would be symmetrically located with respect to the plane of the carbon-oxygen ring, and there would be no fundamental difference between the alpha and beta sugars. But if the oxygen and carbon atoms forming the ring did not lie in one plane, the alpha and beta positions would not be symmetrically located with respect to the carbon-oxygen skeleton, and would be influenced to different degrees by the oxygen of the ring. Presumably this unequal influence would result in differences in the reactivity of the alpha and beta modifications. The positions of the hydrogen and hydroxyl groups of carbons 2,3 , and 4 might also affect the reaction rates of the alpha and beta sugars, either directly or by causing alterations in the conformation of the pyranose ring to give various strainless ring isomers. Thus a comparison of the reaction rates of the alpha and beta pyranoses should provide information about the conformation of the pyranose ring.

\section{BROMINE OXIDATION MEASUREMENTS}

As shown by Isbell and Hudson [36, 37], the aldose sugars are oxidized by bromine water in slightly acid solution to give delta lactones in nearly quantitative yield. Presumably the ring modifications of the sugar are oxidized directly according to the following equation:

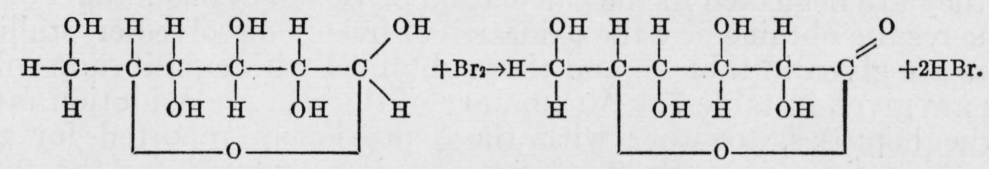

Since this reaction is nearly quantitative and is characteristic of the glycosidic group, it is particularly suitable for investigating the relationships between the stereomeric configurations and the reaction rates. In order to do this, the author developed a set of experimental conditions under which it is possible to follow the oxidation of the separate isomers $[38,39]$. The oxidation is conducted at $0^{\circ} \mathrm{C}$ in the presence of barium carbonate and carbon dioxide. These reagents act as a buffer and maintain a slightly acid reaction, so that the interconversion of the various isomeric modifications of the sugar is slow and the oxidation reaction is rapid. The crystalline sugar is added to the buffered aqueous bromine solution, and the rate of reaction is determined by analysis. The alpha and beta sugars are oxidized at widely different rates, thus providing a convenient means for determining the proportions of these sugars in mixtures. Kinetic studies with equilibrium solutions provide information on the composition of the equilibrium mixture and enable the determination of reaction rates for isomers which are not known in the crystalline state. Heretofore oxidation measurements have been published on the pentoses and on the hexoses with the exception of allose, altrose, and idose. In this paper work on six heptoses is reported.

The procedure previously used was modified slightly to permit the use of smaller quantities of the sugars. The crystalline sugar $(0.210 \mathrm{~g})$ and $1.2 \mathrm{~g}$ of barium carbonate are placed in a $100-\mathrm{ml}$ longneck flask and cooled to $0^{\circ} \mathrm{C}$ in an ice bath. Twenty milliliters of a cold solution, containing $60 \mathrm{~g}$ of barium bromide $\left[\mathrm{Ba}(\mathrm{Br})_{2} \cdot 2 \mathrm{H}_{2} \mathrm{O}\right]$, $20 \mathrm{ml}$ of bromine, and $4 \mathrm{ml}$ of $N$ hydrobromic acid per liter, is added and the mixture is shaken continuously. After definite time intervals, 
the oxidation is stopped by mixing the solution with $5 \mathrm{ml}$ of linseed oil dissolved in $10 \mathrm{ml}$ of benzene. The oil is separated by centrifuging, and the quantity of reducing sugar in the aqueous solution is determined by use of alkaline copper sulphate in the usual manner.

The oxidation of the equilibrium mixture is conducted in like manner except that a solution of the sugar in $10 \mathrm{ml}$ of water is mixed with $1.2 \mathrm{~g}$ of barium carbonate and $10 \mathrm{ml}$ of an oxidizing solution, containing $120 \mathrm{~g}$ of barium bromide, $40 \mathrm{ml}$ of bromine, and $8 \mathrm{ml}$ of $N$ hydrobromic acid per liter. This gives the same concentrations of the reactants as is used for the crystalline sugars. The total bromine in the oxidizing solution is determined by thiosulphate titration, and the concentration of the oxidant (free bromine) and the velocity constants are calculated as described in previous papers [13,39].

In each case the concentration of sugar at zero time should have been $10.5 \mathrm{mg}$ per milliliter, but the concentrations obtained by extrapolation of the results from the analyses to zero time are usually slightly larger than this figure. The difference, which appears to be somewhat larger than the experimental error, cannot be explained at present. It is possible that the bromine reacts during the first few minutes in such manner as to increase temporarily the reducing power of the solution. ${ }^{4}$ The increase is small and by making all calculations on the analytical data the errors are largely compensated, and therefore they are neglected in the calculation of velocity constants.

The results obtained by the oxidation of freshly dissolved crystalline sugars are given in table 6 , and those obtained with equilibrium solutions are given in table 7. A summary of the relative oxidation rates for the heptoses, together with those previously reported for the hexoses, is given in table 8. Each rate is calculated for the total reaction and is based on the rate for the oxidation of $\alpha-d$-glucose as 1 . The relative reaction rates marked by asterisks are obtained by the oxidation of the equilibrium mixtures; the others are from the measurements on the freshly dissolved crystalline sugars.

The results are in accord with the author's earlier observations [21] that isomers in which the hydroxyl groups of carbon 1 are trans to the ring-oxygen are oxidized more rapidly than those in which the hydroxyl and ring-oxygen atoms lie in the same direction. This difference in reactivity is in harmony with the postulation that the two positions are not symmetrically located with respect to the ring-oxygen and that the substances containing the hydroxyl in the cis and trans positions differ fundamentally in structure. This concept is in agreement with a strainless ring structure in which the ring-oxygen is not symmetrically located with respect to the alpha and beta positions. In view of the large number of strainless ring isomers which might be postulated, the determination of the location of the various atoms in space appears to represent an extremely long and complicated problem. By considering the pentoses, heptoses, and higher sugars as substituted hexoses, the problem may be reduced to the determination of the structures of the alpha and beta modifications of the eight hexose types.

\footnotetext{
4 If a sugar solution, buffered with sodium acetate and acetic acid, is treated first with bromine and then with linseed oil to remove the excess bromine, a colorless solution is obtained which on standing several hours regenerates a small quantity of free bromine. Thus it would appear that an addition product, hypobromite, peroxide, or other substance capable of yielding free bromine in the presence of a bromide is formed in small quantity during the oxidation or by the linseed oil treatment. This substance may be a byproduct or an intermediate in the reaction. Such substances may account for the small discrepancy in the analytical data. In any case the byproduct does not accumulate in solution because the sugars appear to be converted to the corresponding monobasic acids or lactones in yields which exceed 95 percent.
} 
$\mathrm{T}_{\mathrm{ABLE}}$ 6.-Bromine oxidations of freshly dissolved crystalline sugars at $0^{\circ} \mathrm{C}$

\begin{tabular}{|c|c|c|c|c|c|c|}
\hline \multirow{2}{*}{$\begin{array}{l}\text { Time after } \\
\text { beginning } \\
\text { oxidation }\end{array}$} & \multirow{2}{*}{$\begin{array}{l}\text { Unoxidized } \\
\text { sugar }\end{array}$} & \multicolumn{3}{|c|}{ A verages for oxidation period } & \multicolumn{2}{|c|}{$\begin{array}{c}\text { Velocity constants } \\
a k=\frac{1}{t} \log \frac{A}{A-X}\end{array}$} \\
\hline & & $\begin{array}{l}\text { Bromide } \\
(\overline{\mathrm{B} r})\end{array}$ & $\underset{\left(\mathrm{Br}_{2}\right)}{\text { Bromine }}$ & $\begin{array}{l}\text { Free bro- } \\
\text { mine }(a)\end{array}$ & $a k \times 10^{3}$ & $k \times 10^{3}$ \\
\hline
\end{tabular}

$a-d$-a-MANNOHEPTOSE (HYDRATE)

\begin{tabular}{|c|c|c|c|c|c|c|}
\hline $\begin{array}{c}\text { Minutes } \\
10 \\
20 \\
30\end{array}$ & $\begin{array}{c}\mathrm{mg} / \mathrm{ml} \\
9.30 \\
8.64 \\
7.91\end{array}$ & $\begin{array}{c}\text { Moles/liter } \\
0.364 \\
.367 \\
.370\end{array}$ & $\begin{array}{c}\text { Moles/liter } \\
0.366 \\
.364 \\
.363\end{array}$ & $\begin{array}{c}\text { Moles/liter } \\
0.087 \\
.085 \\
.084\end{array}$ & $\begin{array}{c}0.00320 \\
.00362\end{array}$ & $\begin{array}{l}37.6 \\
43.1\end{array}$ \\
\hline A verage.- & & & - & 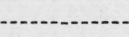 & 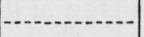 & 40.4 \\
\hline
\end{tabular}

$\beta-d-a$-MANNOHEPTOSE (HYDRATE)

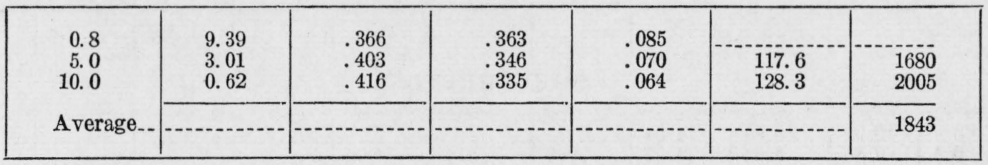

$\alpha-d-\beta$-GULOHEPTOSE

\begin{tabular}{|c|c|c|c|c|c|c|}
\hline $\begin{array}{l}10.0 \\
30.0 \\
60.0\end{array}$ & $\begin{array}{l}9.28 \\
8.23 \\
6.48\end{array}$ & $\begin{array}{l}.366 \\
.372 \\
.382\end{array}$ & $\begin{array}{l}.365 \\
.262 \\
.357\end{array}$ & $\begin{array}{l}.086 \\
.083 \\
.079\end{array}$ & $\begin{array}{c}2.61 \\
2.92\end{array}$ & $\begin{array}{l}31.4 \\
37.0\end{array}$ \\
\hline Average.- & & & & & & 34.2 \\
\hline
\end{tabular}

$\beta-d-\beta$-GALAHEPTOSE

\begin{tabular}{|c|c|c|c|c|c|c|}
\hline $\begin{array}{r}0.6 \\
5.0 \\
10.0\end{array}$ & $\begin{array}{l}9.61 \\
3.06 \\
0.85\end{array}$ & $\begin{array}{l}.364 \\
.403 \\
.423\end{array}$ & $\begin{array}{l}.366 \\
.347 \\
.337\end{array}$ & $\begin{array}{l}.086 \\
.070 \\
.063\end{array}$ & $\begin{array}{l}113.0 \\
112.0\end{array}$ & $\begin{array}{r}1614 \\
1778\end{array}$ \\
\hline Average & - & $\ldots$ & $-\ldots$ & $\ldots$ & $-\ldots$ & 1696 \\
\hline
\end{tabular}

$a-d-a-G A L A H E P T O S E$ (HYDRATE)

\begin{tabular}{|l|c|c|c|c|c|c|}
\hline 10.0 & 10.38 & .361 & .367 & .088 & \\
30.0 & 7.76 & .374 & .361 & .082 & 6.31 & 77.0 \\
60.0 & 5.68 & .385 & .356 & .078 & 5.24 & 67.2 \\
\hline Average. & - & .34 & 72.1 \\
\hline
\end{tabular}

$\beta-d-a-G L U C O H E P T O S E$

\begin{tabular}{|c|c|c|c|c|c|c|}
\hline $\begin{array}{r}0.3 \\
5,0 \\
10.0 \\
20.0 \\
30.0 \\
60.0\end{array}$ & $\begin{array}{r}10.62 \\
7.65 \\
5.49 \\
2.81 \\
1.58 \\
0.47\end{array}$ & $\begin{array}{l}.360 \\
.374 \\
.387 \\
.404 \\
.415 \\
.428\end{array}$ & $\begin{array}{l}.368 \\
.361 \\
.355 \\
.346 \\
.341 \\
.334\end{array}$ & $\begin{array}{l}.088 \\
.082 \\
.077 \\
.070 \\
.066 \\
.061\end{array}$ & $\begin{array}{l}30.3 \\
29.5 \\
29.3 \\
27.8 \\
22.7\end{array}$ & $\begin{array}{l}370 \\
383 \\
419 \\
421 \\
372\end{array}$ \\
\hline A verage_. & & & & & 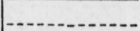 & 393 \\
\hline
\end{tabular}

$\beta-d-\beta$-GLUCOHEPTOSE

\begin{tabular}{|c|c|c|c|c|c|c|}
\hline $\begin{array}{r}0.7 \\
5.0 \\
10.0 \\
20.0 \\
60.0\end{array}$ & $\begin{array}{r}10.74 \\
7.75 \\
5.58 \\
3.47 \\
1.09\end{array}$ & $\begin{array}{l}.360 \\
.374 \\
.386 \\
.400 \\
.421\end{array}$ & $\begin{array}{l}.368 \\
.361 \\
.355 \\
.348 \\
.338\end{array}$ & $\begin{array}{l}.088 \\
.082 \\
.077 \\
.071 \\
.064\end{array}$ & $\begin{array}{l}33.0 \\
30.6 \\
25.4 \\
16.8\end{array}$ & $\begin{array}{l}-\overline{402} \\
397 \\
358 \\
263\end{array}$ \\
\hline Average.. & & & & & $\ldots$ & 355 \\
\hline
\end{tabular}


TABLE 7.-Bromine oxidations at $0^{\circ} \mathrm{C}$ of aqueous sugar solutions in equilibrium at the beginning of the oxidation

\begin{tabular}{|c|c|c|c|c|c|c|c|c|c|c|}
\hline \multirow{3}{*}{ Time } & \multicolumn{3}{|c|}{ Unoxidized sugar } & \multicolumn{3}{|c|}{$\begin{array}{l}\text { Averages for the oxidation } \\
\text { period }\end{array}$} & \multicolumn{4}{|c|}{ Velocity constants } \\
\hline & \multirow{2}{*}{ Total } & \multirow{2}{*}{$\begin{array}{l}\text { More } \\
\text { reactive } \\
\text { fraction }\end{array}$} & \multirow{2}{*}{$\begin{array}{l}\text { Less } \\
\text { reactive } \\
\text { fraction }\end{array}$} & \multirow{2}{*}{$\begin{array}{l}\text { Bro- } \\
\text { mide } \\
(\mathrm{Br})\end{array}$} & \multirow{2}{*}{$\begin{array}{l}\text { Bro- } \\
\text { mine } \\
\left(\mathrm{Br}_{2}\right)\end{array}$} & \multirow{2}{*}{$\begin{array}{c}\text { Free } \\
\text { bromine } \\
(a)\end{array}$} & \multicolumn{2}{|c|}{$\begin{array}{l}\text { More reactive } \\
\text { fraction }\end{array}$} & \multicolumn{2}{|c|}{$\begin{array}{l}\text { Less reactive } \\
\text { fraction }\end{array}$} \\
\hline & & & & & & & $a k_{B} \times 10^{3}$ & $k_{B} \times 10^{3}$ & $a k_{\Delta} \times 10^{3}$ & $k_{\Delta} \times 10^{3}$ \\
\hline \multicolumn{11}{|c|}{$d$-a-MANNOHEPTOSE (HYDRATE) } \\
\hline \multirow{5}{*}{$\begin{array}{r}\text { Minutes } \\
0 \\
0.5 \\
5.0 \\
20.0 \\
60.0\end{array}$} & $\mathrm{mg} / \mathrm{ml}$ & & & $\underset{\text { liter }}{\text { Moles/ }}$ & $\begin{array}{c}\text { Moles/ } \\
\text { liter }\end{array}$ & $\begin{array}{c}\text { Moles/ } \\
\text { liter }\end{array}$ & & & & \\
\hline & $\begin{array}{r}10.47 \\
9.43\end{array}$ & $\begin{array}{l}7.04 \\
6.02\end{array}$ & $\begin{array}{l}\text { 3. } 43 \\
\text { 3. } 40\end{array}$ & 0.365 & 0.375 & 0.090 & & & & \\
\hline & 4.76 & 1.48 & 3. 34 & .372 & .372 & .087 & 135.4 & 1,556 & & $\because-$ \\
\hline & $\begin{array}{l}2.88 \\
2.12\end{array}$ & - nons & $\begin{array}{l}2.88 \\
2.12\end{array}$ & $\begin{array}{l}.392 \\
.420\end{array}$ & $\begin{array}{l}.358 \\
.347\end{array}$ & $\begin{array}{l}.076 \\
.067\end{array}$ & . & $-1-1-1$ & 3.33 & 49.7 \\
\hline & - n....... & $\ldots . . .$. & - & 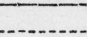 & 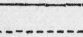 & 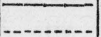 & ........... & 1,556 & - & 49.7 \\
\hline
\end{tabular}

$d$ - $\beta$-GULOHEPTOSE

\begin{tabular}{|c|c|c|c|c|c|c|c|c|c|c|}
\hline $\begin{array}{r}0 \\
0.5 \\
5.0 \\
20.0 \\
60.0 \\
120.0\end{array}$ & $\begin{array}{r}10.92 \\
9.85 \\
5.22 \\
3.55 \\
2.75 \\
2.08\end{array}$ & $\begin{array}{r}6.88 \\
5.83 \\
1.31 \\
\\
\end{array}$ & $\begin{array}{l}4.04 \\
4.02 \\
3.91 \\
3.55 \\
2.75 \\
2.08\end{array}$ & $\begin{array}{l}.363 \\
.383 \\
.409 \\
.422 \\
.430\end{array}$ & $\begin{array}{l}.376 \\
.365 \\
.354 \\
.347 \\
.343\end{array}$ & $\begin{array}{l}.090 \\
.081 \\
.071 \\
.066 \\
.064\end{array}$ & 144.1 & 1,779 & $\begin{array}{l}2.77 \\
2.32\end{array}$ & $\begin{array}{r}42.0 \\
36.2\end{array}$ \\
\hline A verage... & & - & & & & . & & 1,779 & & 39.1 \\
\hline
\end{tabular}

$d$ - $\beta$-GALAHEPTOSE

\begin{tabular}{|c|c|c|c|c|c|c|c|c|c|c|}
\hline $\begin{array}{r}0 \\
0.5 \\
5.0 \\
20.0 \\
60.0 \\
120.0\end{array}$ & $\begin{array}{r}11.27 \\
9.94 \\
5.21 \\
3.85 \\
3.31 \\
2.59\end{array}$ & $\begin{array}{r}7.08 \\
5.77 \\
1.11 \\
\end{array}$ & $\begin{array}{l}4.19 \\
4.18 \\
4.10 \\
3.85 \\
3.31 \\
2.59\end{array}$ & $\begin{array}{l}.363 \\
.386 \\
.409 \\
.420 \\
.426\end{array}$ & $\begin{array}{l}.376 \\
.365 \\
.354 \\
.348 \\
.345\end{array}$ & $\begin{array}{l}.090 \\
.080 \\
.071 \\
.067 \\
.065\end{array}$ & 158.9 & $\begin{array}{r}1,987 \\
\end{array}$ & $\begin{array}{l}1.64 \\
1.72\end{array}$ & $\begin{array}{l}0 . . \\
24.5 \\
26.5\end{array}$ \\
\hline A verage ... & - & - & & & & & ...- & 1,987 & & 25.5 \\
\hline
\end{tabular}

$d$-a-GALAHEPTOSE (HYDRATE)

\begin{tabular}{|c|c|c|c|c|c|c|c|c|c|c|}
\hline $\begin{array}{l}0 \\
0.5 \\
5.0 \\
8.0 \\
20.0 \\
30.0 \\
60.0\end{array}$ & $\begin{array}{r}10.91 \\
10.46 \\
8.56 \\
7.93 \\
6.75 \\
5.91 \\
4.58\end{array}$ & $\begin{array}{r}2.25 \\
1.86 \\
0.43 \\
.10 \\
\\
\end{array}$ & $\begin{array}{l}8.66 \\
8.60 \\
8.13 \\
7.83 \\
6.75 \\
5.91 \\
4.58\end{array}$ & $\begin{array}{l}.361 \\
.369 \\
.374 \\
.380 \\
.389 \\
.399\end{array}$ & $\begin{array}{l}.377 \\
.373 \\
.371 \\
.367 \\
.363 \\
.357\end{array}$ & $\begin{array}{l}.091 \\
.087 \\
.086 \\
.083 \\
.079 \\
.074\end{array}$ & $\begin{array}{r}141.3 \\
169.3 \\
\end{array}$ & $\begin{array}{r}1,624 \\
1,969\end{array}$ & $\begin{array}{l}57 \\
4.21\end{array}$ & $\begin{array}{l}0 . . \\
56.9\end{array}$ \\
\hline A verage... & $\ldots . . .$. & -.-. & 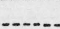 & & & & & 1,797 & & 65.0 \\
\hline
\end{tabular}

$d-\alpha$-GLUCOHEPTOSE

\begin{tabular}{|c|c|c|c|c|c|c|c|c|c|c|}
\hline \begin{tabular}{r}
\multicolumn{1}{c}{0} \\
0.6 \\
5.0 \\
20.2 \\
60.0 \\
120.0
\end{tabular} & $\begin{array}{r}11.12 \\
10.56 \\
7.47 \\
3.06 \\
0.88 \\
0.61\end{array}$ & $\begin{array}{r}9.81 \\
9.26 \\
6.21 \\
1.92 \\
\\
\end{array}$ & $\begin{array}{l}1.31 \\
1.30 \\
1.27 \\
1.15 \\
0.88 \\
0.61\end{array}$ & $\begin{array}{l}.360 \\
.375 \\
.395 \\
.428 \\
.441\end{array}$ & $\begin{array}{r}.378 \\
.372 \\
.362 \\
.345 \\
.338\end{array}$ & $\begin{array}{r}.091 \\
.086 \\
.077 \\
.065 \\
.060\end{array}$ & $\begin{array}{r}39.6 \\
35.0 \\
\hdashline\end{array}$ & $\begin{array}{r}460 \\
455 \\
-\end{array}$ & 2.65 & י4.2 \\
\hline A verage... & 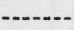 & - & -2 & $\ldots$ & & & & 458 & & 44.2 \\
\hline
\end{tabular}

$d$ - $\beta$-GLUCOHEPTOSE

\begin{tabular}{|c|c|c|c|c|c|c|c|c|c|c|}
\hline $\begin{array}{r}0 \\
0.5 \\
5.0 \\
20.0 \\
60.0 \\
120.0\end{array}$ & $\begin{array}{r}10.74 \\
10.41 \\
8.10 \\
4.18 \\
1.78 \\
1.37\end{array}$ & $\begin{array}{r}8.39 \\
8.12 \\
5.85 \\
2.07 \\
\end{array}$ & $\begin{array}{l}2.35 \\
2.35 \\
2.30 \\
2.14 \\
1.78 \\
1.37\end{array}$ & $\begin{array}{r}.360 \\
.369 \\
.393 \\
.426 \\
.432\end{array}$ & $\begin{array}{r}.378 \\
.373 \\
.361 \\
.350 \\
.342\end{array}$ & $\begin{array}{r}.091 \\
.087 \\
.077 \\
.067 \\
.063\end{array}$ & $\begin{array}{r}31.8 \\
30.6 \\
\end{array}$ & $\begin{array}{r}366 \\
397 \\
\end{array}$ & 1.90 & 30.2 \\
\hline Average... & & & & & & & & 382 & & 30.2 \\
\hline
\end{tabular}


TABLE 8.-Rates of oxidation of the alpha and beta sugars in aqueous solutions at $0^{\circ} \mathrm{C}$ containing 0.05 mole of sugar, and approximately 0.08 mole of free bromine per liter and buffered with barium carbonate and carbon dioxide

\begin{tabular}{|c|c|c|c|c|}
\hline \multirow{3}{*}{ Sugar } & \multicolumn{2}{|c|}{ Relative reaction rates } & \multirow{3}{*}{$k_{\beta} / k_{\alpha}$} & \multirow{3}{*}{$\begin{array}{l}\text { Less reac- } \\
\text { tive fraction } \\
\text { in equili- } \\
\text { brium } \\
\text { solution }\end{array}$} \\
\hline & \multicolumn{2}{|c|}{$\frac{k_{\text {sugar }}}{k_{\alpha-d-\mathrm{gl} \mathrm{ueose}}}$} & & \\
\hline & $\underset{(c i s)}{\text { Alpha form }}$ & $\begin{array}{c}\text { Beta form } \\
\text { (trans) }\end{array}$ & & \\
\hline
\end{tabular}

HEPTOSES

\begin{tabular}{|c|c|c|c|c|}
\hline $\begin{array}{l}d-\beta \text {-Galaheptose } \\
d-\alpha \text {-Galaheptose } \\
d-\alpha \text {-Mannoheptose } \\
d-\beta \text {-Guloheptose } \\
d-\alpha \text {-Glucoheptose } \\
d-\beta \text {-Glucoheptose }\end{array}$ & $\begin{array}{r}0.8 \\
2.3 \\
1.3 \\
1.1 \\
a \\
1.4 \\
a .9\end{array}$ & $\begin{array}{r}53 \\
\text { a } 56 \\
58 \\
\text { a } 56 \\
12 \\
11\end{array}$ & $\begin{array}{r}66 \\
25 \\
46 \\
52 \\
9 \\
12\end{array}$ & $\begin{array}{r}\text { Percent } \\
37 \\
79 \\
33 \\
37 \\
12 \\
22\end{array}$ \\
\hline
\end{tabular}

HEXOSES

\begin{tabular}{|c|c|c|c|c|}
\hline $\begin{array}{l}\text { Glucose } \\
\text { Mannose } \\
\text { Galactose. } \\
\text { Gulose. } \\
\text { Talose. }\end{array}$ & $\begin{array}{l}1.0 \\
1.6 \\
1.3 \\
2.2 \\
2.4\end{array}$ & $\begin{array}{r}39 \\
24 \\
50 \\
13 \\
26\end{array}$ & $\begin{array}{r}39 \\
15 \\
38 \\
6 \\
11\end{array}$ & $\begin{array}{l}37 \\
69 \\
31 \\
18 \\
56\end{array}$ \\
\hline
\end{tabular}

a Rate derived from the measurement with the sugar present in the equilibrium solution.

The striking parallelism between the heptose sugars and the structurally related hexoses is illustrated clearly by their behavior on bromine oxidation and by the equilibrium which is established when they are dissolved in water. Freshly dissolved $\beta$ - $d$ - $\beta$-galaheptose $[40,46]$ is oxidized by bromine rapidly at a rate comparable to the oxidation of the structurally related $\beta$-l-glucose. The oxidation of the equilibrium solution of the heptose shows the presence of about 37 percent of slowly oxidizable modification, supposedly $\alpha-d-\beta$-galaheptose. The proportion of this constituent parallels the proportion of the slowly oxidizable substance in equilibrium solutions of glucose [39]. Furthermore, the optical rotation of $\beta-d-\beta$-galaheptose is close to that of $\beta-l$-glucose and the optical rotation of the sugar in equilibrium is near to that of $l$-glucose. Obviously the equilibrium states for the two sugars are similar.

The oxidation of $\alpha-d$ - $\alpha$-galaheptose with bromine water takes place slowly and resembles the oxidation of the alpha sugars in general. Consequently the bromine oxidation measurements support its classification as alpha. The similarity of this sugar to $\alpha$-l-mannose was noted by Hann, Merrill, and Hudson [28] with respect to other properties but they called it $\beta$ - $d$ - $\alpha$-galaheptose in accordance with Hudson's nomenclature.

As may be seen by inspection of the curves given in figures 5 and 6 , the oxidation of the equilibrium solution of $d$ - $\alpha$-galaheptose differs from that of $d-\beta$-galaheptose in that it contains only a small proportion of the rapidly oxidizable sugar. This characteristic was also found [13] for equilibrium solutions of $d$-mannose, $d$-lyxose, and $l$-rhamnose. It is thus apparent that the equilibrium state for $d$ - $\alpha$-galaheptose is analogous to that of mannose.

The heretofore described modification of $d$ - $\alpha$-mannoheptose $(+85)$ [41] appears to be a mixture of the alpha and beta isomers, perhaps forming a double compound of the type described by Hockett and 


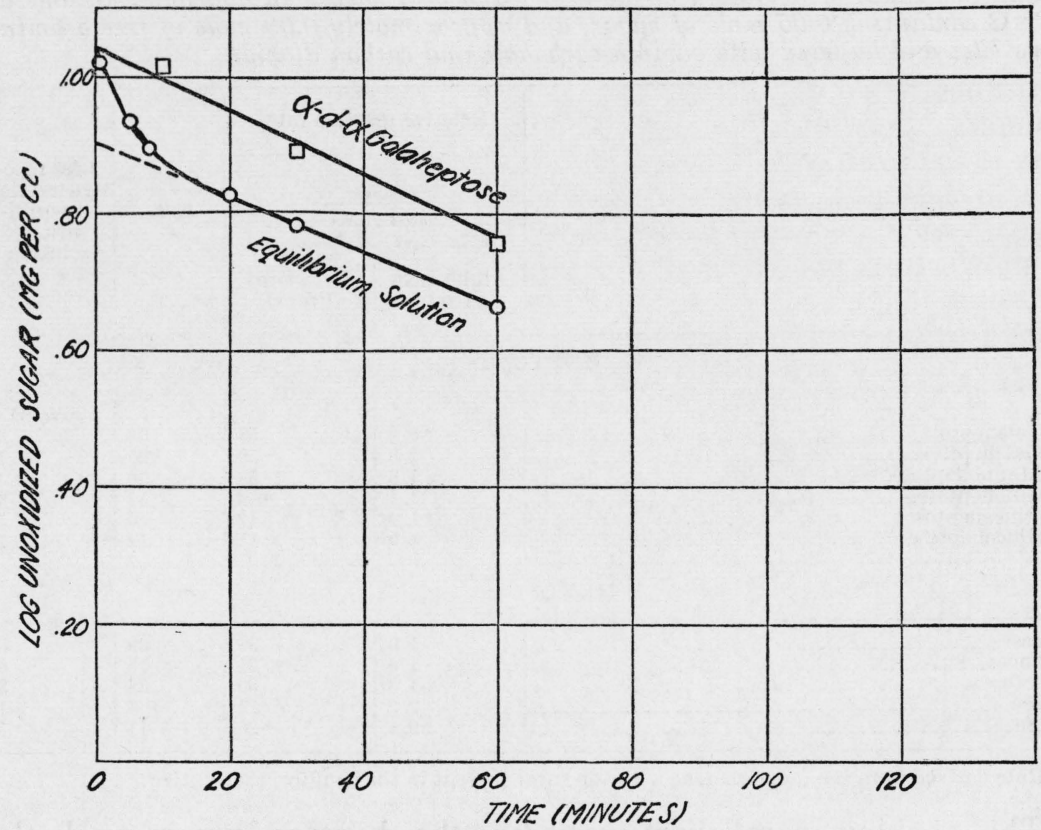

Figure 5.-Bromine oxidation of $d$ - $\alpha$-galaheptose.

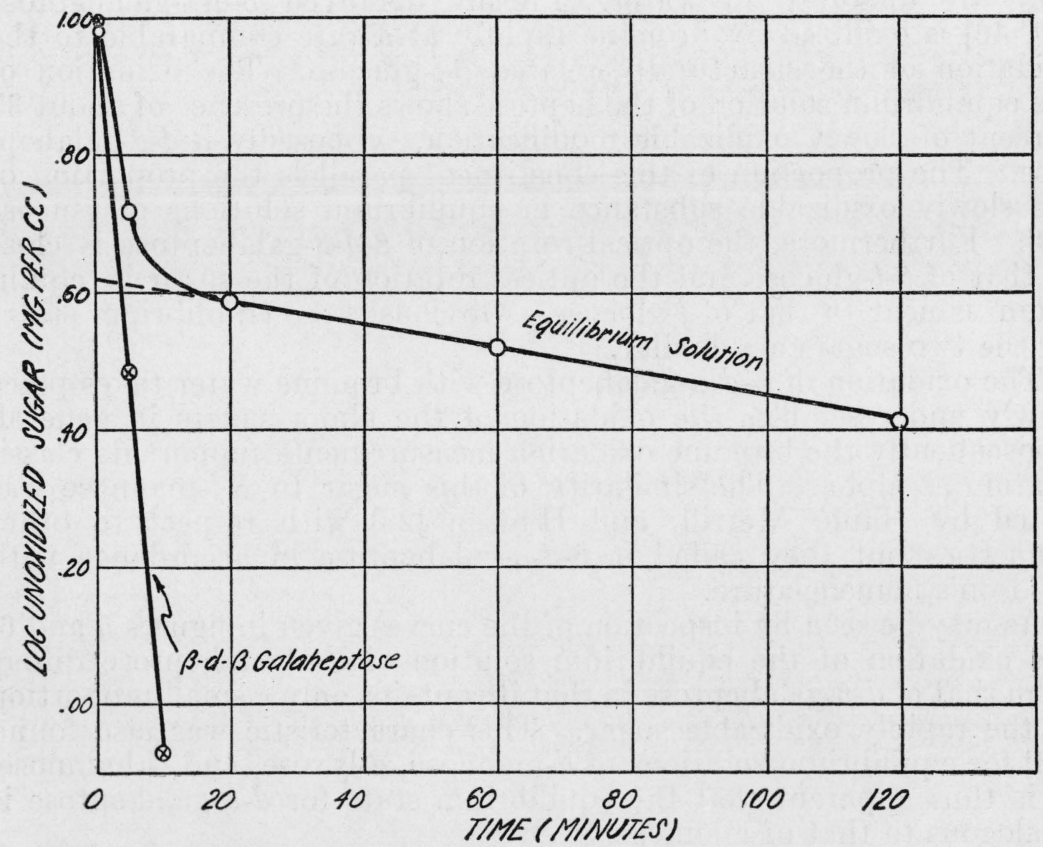

FIGURE 6.-Bromine oxidation of $d$ - $\beta$-galaheptose. 
Hudson [42]. As may be observed from figure 7 the oxidation of this substance proceeds rapidly until approximately half of the original sugar is oxidized and then more slowly as the less reactive component continues to be oxidized. The author has now prepared $\alpha-d$ - $\alpha$-mannoheptose in what appears to be a pure state. As illustrated in figure 7 , it is oxidized at a uniform rate and gives $[\alpha]^{20}{ }_{D}=+120$. Crystalline $\beta-d-\alpha$-mannoheptose monohydrate was also prepared. This sugar, which is structurally related to $\beta$ - $d$-galactose, is oxidized rapidly as shown in figure 7. The equilibrium solution of $d$ - $\alpha$-mannoheptose contains 33 percent of slowly oxidizable material. This proportion compares favorably to the percentages of 31,32 , and 37 found for the

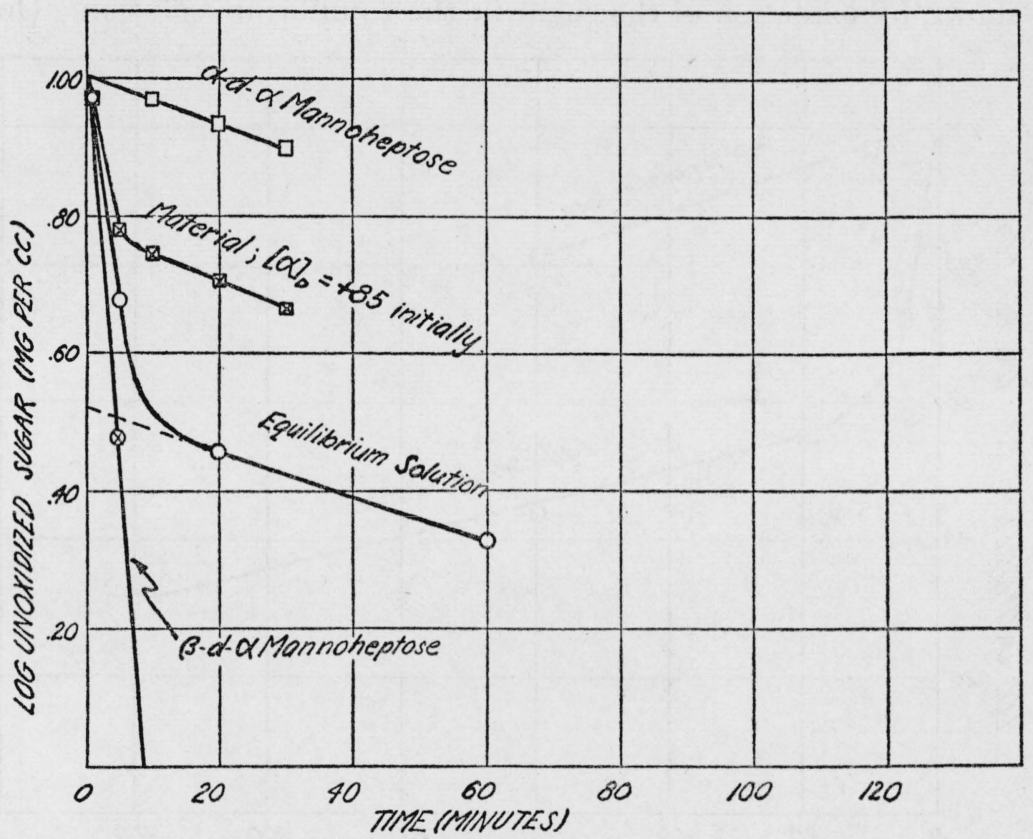

Figure 7.-Bromine oxidation of $d$ - $\alpha$-mannoheptose.

structurally related sugars, $d$-galactose, $l$-arabinose, and $d$ - $\beta$-guloheptose. Furthermore, it will be recalled that the complex mutarotations of $\alpha$ - and $\beta-d-\alpha$-mannoheptose resemble the complex mutarotations of $\alpha$ - and $\beta$ - $d$-galactose.

The crystalline guloheptose which was originally prepared by La Forge [43] and called $\alpha$-guloheptose has been designated $\alpha-d-\beta-$ guloheptose. ${ }^{5}$ It is structurally related to $\alpha$-l-galactose and exhibits

5 The two epimeric heptoses formed from glucose by the cyanhydrin synthesis were designated $\alpha$ glucoheptose and $\beta$-glucoheptose by Fischer. The designation alpha and beta in this case signifies which one of the parent acids was separated first, and does not have anything to do with the two modifications of the reducing group in the sugars. Attempts have been made to clarify this double use of alpha and beta but no uniform system has been adopted. Elsner (Tollens-Elsner, Kurzes Handbuch der Kohlenhydrate, page 390) discusses the subject and proposes the use of the letters "a" and "b" instead of alpha and beta for distinguishing between the epimeric sugars. The Greek letters are employed in Chemical Abstracts, and consequently they will be used in this paper for naming the epimeric heptoses as well as for naming the two pyranose modifications. The position preceding the $d$ or $l$ symbol is used exclusively for characterizing the configuration of the reducing group, while the position following the $d$ or $l$ is used for indicating the configuration of the second carbon. Originally the heptonic acid most easily separated was designated alpha. It seems advisable to rationalize this nomenclature by giving alpha and beta a structural rather than a historic significance. Thus the two epimeric substances formed by extending the carbon chain might be designated "alpha" and "beta" according to whether the hydroxyl of the new asymmetric carbon is of the same or different configuration from that of the terminal asymmetric carbon (the one which determines the $d$ or $l$ classification). Then the guloheptose prepared by La Forge and called $\alpha$-guloheptose would be designated $\alpha$ - $d$ - $\beta$-guloheptose and its enantiomorphic isomer would be $\alpha$-l- $\beta$-guloheptose. 
analogous properties. The oxidation of the crystalline sugar is represented by the upper curve of figure 8 . The oxidation of the sugar in the equilibrium solution resembles the oxidation of galactose and gives clear evidence for the existence of a large proportion of the rapidly oxidizable modification, supposedly $\beta-d$ - $\beta$-guloheptose.

The oxidation of $d-\alpha$-glucoheptose resembles that of the structurally related hexose, $d$-gulose, in that there is relatively small difference in the rate of oxidation of the freshly dissolved crystalline sugar and of the sugar in the equilibrium solution. The crystalline sugar, which is classified as beta, is structurally related to $\beta$ - $d$-gulose. It is oxidized about nine times as rapidly as the alpha modification whose presence is shown by oxidation of the sugar in the equilibrium solution. Only

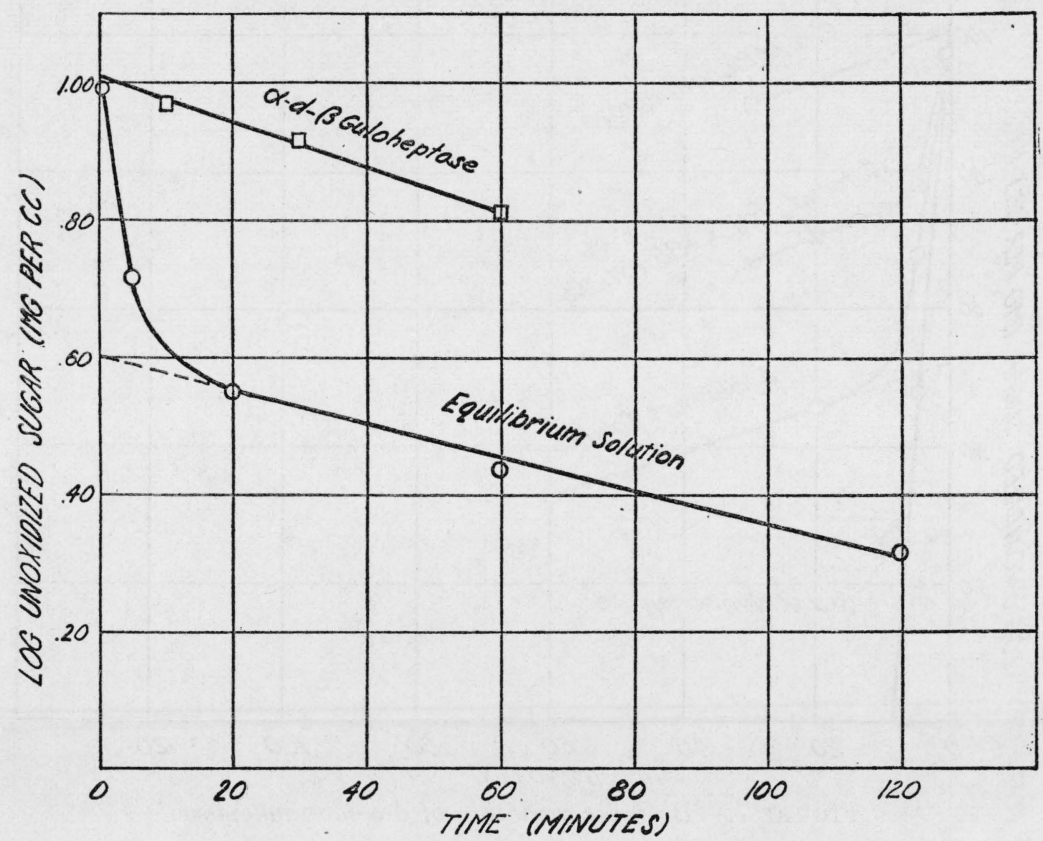

FIgURE 8.-Bromine oxidation of $d$ - $\beta$-guloheptose.

12 percent of the alpha modification is present, which accounts for the relatively small difference in the behavior of the freshly dissolved crystalline sugar and that of the sugar in the equilibrium solution.

The reactions and properties of $\beta-d-\beta$-glucoheptose are of unusual importance because it is the first crystalline sugar to be obtained which has the structure of $d$-idose. It represents an unexplored field of carbohydrate chemistry, namely, the idopyranoses. The crystalline modification (tentatively designated beta) is oxidized more slowly than any beta sugar heretofore investigated, but it is also oxidized more rapidly than any alpha sugar. The oxidation of the equilibrium solution reveals that it contains about 22 percent of a slowly oxidized modification and that the equilibrium lies in the direction of the form which is known in the crystalline state and which is designated beta. The hydroxyl of carbon 1 of this substance, supposedly lies on the same side of the ring as the hydroxyl of carbon 2 . If this be true, this 


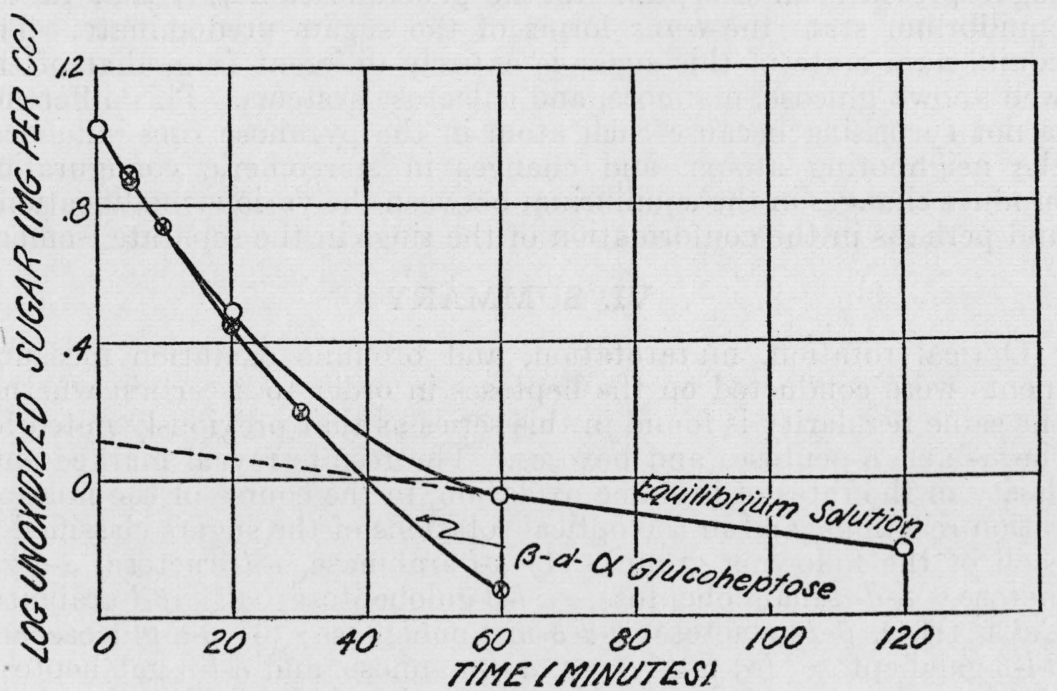

Figure 9.-Bromine oxidation of $d$ - $\alpha$-glucoheptose.

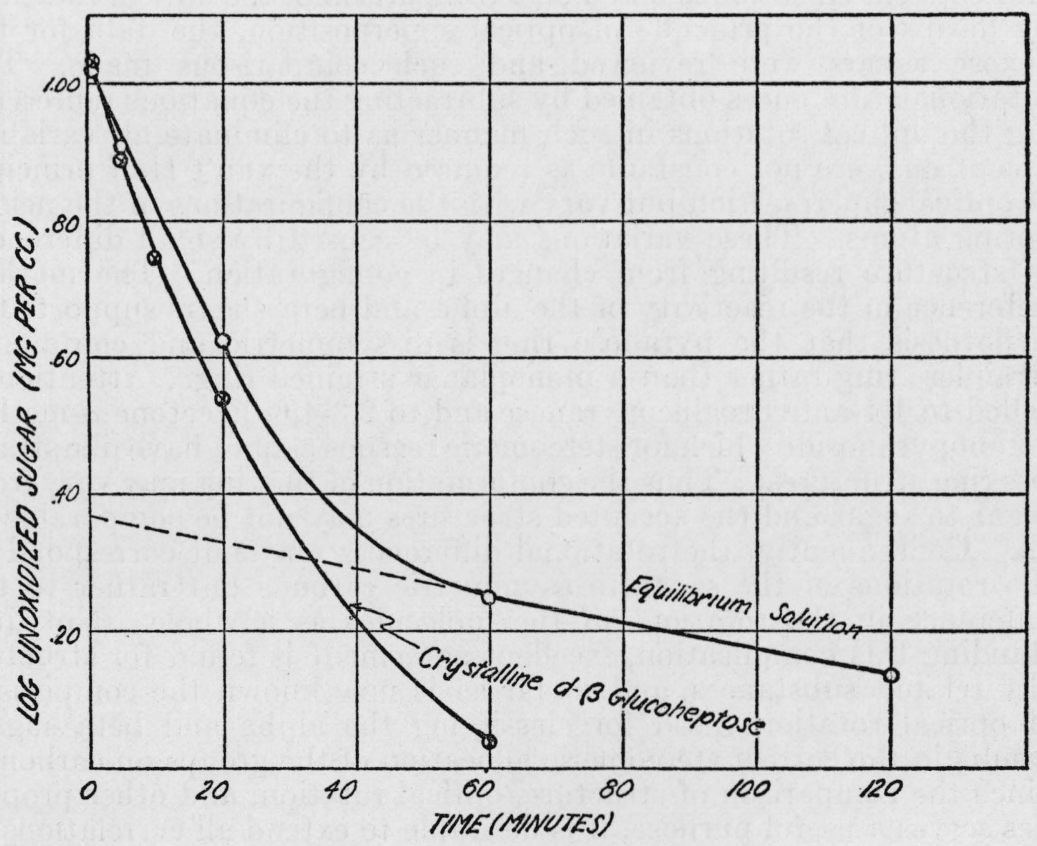

FiguRe 10.-Bromine oxidation of $d$ - $\beta$-glucoheptose. 
sugar provides an exception to the generalization [44] that in the equilibrium state the trans forms of the sugars predominate. The equilibrium state of this sugar is entirely different from that of the well known glucose, mannose, and galactose systems. This difference is not surprising because each atom in the pyranose ring influences the neighboring atoms, and changes in stereomeric configuration produce changes in the equilibrium between the various modifications, and perhaps in the conformation of the rings in the separate isomers.

\section{SUMMARY}

Optical rotation, mutarotation, and bromine oxidation measurements were conducted on the heptoses in order to ascertain whether the same regularity is found in this series as that previously noted for the $\alpha$ - and $\beta$-pentoses and hexoses. The results reveal marked similarity in the rates of bromine oxidation, in the course of the mutarotation reactions, and in the optical rotations of the sugars classified in each of the following groups: (1) $\alpha$-l-arabinose, $\alpha$-l-fructose, $\alpha$ - $d$-galactose, $\alpha-d-\alpha$-mannoheptose, $\alpha-l-\beta$-guloheptose; (2) $\beta$-l-arabinose $\mathrm{CaCl}_{2} .4 \mathrm{H}_{2} \mathrm{O}, \beta$ - $d$-galactose, $\beta$ - $d$ - $\alpha$-mannoheptose; (3) $\beta$ - $d$-glucose and $\beta$-l- $\beta$-galaheptose; (4) $\alpha$ - $d$-lyxose, $\alpha$ - $d$-mannose, and $\alpha$ - $l$ - $\alpha$-galaheptose; (5) $\beta$ - $d$-gulose and $\beta$ - $d$ - $\alpha$-glucoheptose; (6) $\beta$ - $d$-idose and $\beta-d$ - $\beta$-glucoheptose. In every case the beta aldose is oxidized by bromine water more rapidly than the alpha, and the equilibrium solution contains two or more substances which differ in reaction rates. Since the alpha and beta classification is based on a comparison of the optical rotations by means of the principle of optical superposition, the data for the hexose sugars were reviewed and such comparisons made. The rotational differences obtained by subtracting the equations representing the optical rotations in such manner as to eliminate all variables except one, are not constants as required by the van't Hoff principle of optical superposition but vary with the configurations of the neighboring atoms. These variations may be caused by small differences in structure resulting from changes in configuration. The marked difference in the reactivity of the alpha and beta sugars supports the hypothesis that the pyranose ring is dissymmetric and contains a strainless ring rather than a monoplanar strained ring. Attention is called to 1,4-anhydroglucopyranose and to 2,3-4,6-diacetone $\alpha$-methyl mannopyranoside which for stereomeric reasons cannot have like strainless ring structures. Thus the conformation of the ring may vary from sugar to sugar and the accepted structures may not be comparable at all. Consequently, the rotational differences may not correspond to the rotations of the separate asymmetric carbons but rather to the difference in the rotations of the molecules as a whole. Notwithstanding this complication, excellent agreement is found for structurally related substances, and so far as is now known the comparison of optical rotations used for classifying the alpha and beta sugars results in the correct stereomeric allocation of the groups on carbon 1. Since the comparison of structure, optical rotation, and other properties serves a useful purpose, it is desirable to extend all correlations as far as the experimental work justifies. The rules of isorotation should be modified to take into account the configuration of the neighboring atoms, perhaps by restricting the comparisons to substances of analogous configuration and basing the classification on the eight fundamental pyranose types. 
The specific rotations $[\alpha]_{D}^{20}$ of the heptoses prepared in this investigation are represented by the following equations in which $t$ is time measured in minutes after the sugar is dissolved in water.

$\alpha-d$ - $\alpha$-Mannoheptose hydrate $=+3.4 \times 10^{-.0485 t}+51.9 \times 10^{-.00391 t}+64.7$.

$\beta-d-\alpha$-Mannoheptose hydrate $=+2.9 \times 10^{-.0480 t}-25.1 \times 10^{-.00384 t}+64.5$.

$\alpha-d-\beta$-Guloheptose $=-3.9 \times 10^{-.0597 t}-51.5 \times 10^{-.00533 t}-65.1$.

$\beta-d-\beta$-Glucoheptose $=+11.3 \times 10^{-.050 t}-11.3 \times 10^{-.0108 t}-0.1$.

$\alpha-d-\alpha$-Galaheptose hydrate $=-11.2 \times 10^{-.00471} t-14.0$.

$\beta-d-\beta$-Galaheptose $=+34.9 \times 10^{-.00197 t}-54.1$.

$\beta-d-\alpha-$ Glucoheptose $=-8.5 \times 10^{-.0080 t}-20.2$.

Pure $\alpha$ - and $\beta-d-\alpha$-mannoheptose and the mutarotation of $\beta-d-\beta$ guloheptose are reported for the first time. The mutarotation constants for $\alpha-d-\alpha$-galaheptose hydrate and $\beta-d-\alpha$-glucoheptose are substantially lower than those found in the literature. A comparison of the mutarotations of the heptoses with those of structurally similar hexoses reveals that the configuration of the five carbon atoms comprising the pyranose ring determines the equilibrium proportions of the various stereomeric modifications. Sugars having the $\alpha$ - $d$-galactose structure exhibit mutarotations similar to that of $\alpha$ - $d$-galactose, while those having the $\beta$ - $d$-galactose structure are like that sugar. Correlations of this character apply throughout the series.

\section{REFERENCES}

[1] Van't Hoff, The Arrangement of Atoms in Space (translated by Eiloart), page 160 (Longmans, Green and Co., London, 1898).

[2] K. Freudenberg, Stereochemie, page 423 (Franz Deuticke, Leipzig and Wien, 1933).

[3] W. N. Haworth and E. L. Hirst, J. Chem. Soc. 1930, 2615.

[4] C. S. Hudson, J. Am. Chem. Soc. 31, 66 (1909).

[5] C. S. Hudson, BS Sci. Papers 21, 241 (1926) S533.

[6] H. S. Isbell, BS J. Research 5, 1179 (1930) RP253.

[7] H. S. Isbell, BS J. Research 3, 1041 (1929) RP128.

[8] H. S. Isbell and W. W. Pigman, J. Research NBS 16, 553 (1936) RP892.

[9] F. P. Phelps and F. J. Bates, J. Am. Chem. Soc. 56, 1250 (1934).

[10] N. K. Richtmyer and C. S. Hudson, J. Am Chem. Soc. 5\%, 1716 (1935).

[11] M. A. Rosanoff, J. Am. Chem. Soc. 28, 525 (1906); 29, 536 (1907).

[12] K. Freudenberg and R. Kuhn, Ber. deut. chem. Ges. 64, 703 (1931).

[13] H. S. Isbell and W. W. Pigman, J. Research NBS 18, 141 (1937) RP969; J. Org. Chem. 1, no. 6 (1937).

[14] W. C. Austin and F. L. Humoller, J. Am. Chem. Soc. 56, 1153 (1934).

[15] J. Böeseken, The Configuration of the Saccharides (translated by S. Coffey), page 57 (A. W. Sijhoff, Leyden, 1923).

[16] J. Böeseken and H. Couvert, Rec. trav. chim. Pays-Bas 40, 354 (1921).

[17] B. Verschurer, Rec. trav. chim. Pays-Bas 47, 123, 423 (1928).

[18] H. S. Isbell, BS J. Research 8, 3 (1932) RP396.

[19] C. S. Hudson, J. Am. Chem. Soc. 48, 1434 (1926).

[20] T. M. Lowry, Optical Rotatory Power, p. 429. (Longmans, Green and Co., London, 1935).

[21] H. S. Isbell, J. Chem. Educ. 12, 96 (1935).

[22] M. A. Rosanoff, J. Am. Chem. Soc. 28, 114 (1906).

[23] F. B. La Forge and C. S. Hudson, J. Biol. Chem. 30, 61 (1917).

[24] G. Bertrand Bul. soc. chim. [4] 5, 629 (1909).

[25] C. S. Hudson, J. Am. Chem. Soc. 52, 1693 (1930).

[26] C. S. Hudson, Olive Hartley, and C. B. Purves, J. Am. Chem. Soc. 56, 1248 (1934).

[27] G. F. Smith and T. M. Lowry, J. Chem. Soc. 1928, 666.

[28] R. M. Hann, Alice T. Merrill, and C. S. Hudson, J. Am. Chem. Soc. 5\%, 2100 (1935).

[29] C. S. Hudson and E. Yanovsky, J. Am. Chem. Soc. 39, 1037 (1917).

[30] W. N. Haworth, The Constitution of Sugars, p. 90 (Edward Arnold \& Co., London, 1929). 
[31] H. Hibbert and J. S. Allen, J. Am. Chem. Soc. 54, 4115 (1932); 56, 1398 (1934).

[32] E. G. Cox, J. Chem. Soc. 1931, 2313; 1932, 138, 1844; 1935, 1495.

[33] O. L. Sponsler and W. H. Dore, Annual Review of Biochemistry, page 66 (1936).

[34] F. Micheel and K. Hess, Ber. deut. chem. Ges. 60, 1898 (1927).

[35] R. G. Ault, W. N. Haworth, and E. L. Hirst, J. Chem. Soc. 1935, 1012.

[36] H. S. Isbell and C. S. Hudson, BS J. Research 8, 327 (1932) RP418.

[37] H. S. Isbell, BS J. Research 8, 615 (1932) RP441.

[38] H. S. Isbell, J. Am. Chem. Soc. 54, 1692 (1932).

[39] H. S. Isbell and W. W. Pigman, BS J. Research 10, 337 (1933) RP 534.

[40] E. Fischer, Liebigs Ann. Chem. 288, 154 (1895).

[41] E. Fischer and F. Passmore, Ber. deut. chem. Ges. 23, 2226 (1890).

[42] R. C. Hockett and C. S. Hudson, J. Am. Chem. Soc. 53, 4455 (1931).

[43] F. B. La Forge, J. Biol. Chem. 41, 251 (1920).

[44] W. N. Haworth and E. L. Hirst, J. Chem. Soc. 1928, 1226.

[45] H. S. Isbell, J. Am. Chem. Soc. 56, 2789 (1934).

[46] R. M. Hann and C. S. Hudson, J. Am. Chem. Soc. 59, 550 (1937).

Washington, March 23, 1937. 